\title{
Pericytes as Inducers of Rapid, Matrix Metalloproteinase- 9-Dependent Capillary Damage during Ischemia
}

\author{
Robert G. Underly, ${ }^{1}$ Manuel Levy, ${ }^{1}$ David A. Hartmann, ${ }^{1}$ Roger I. Grant, ${ }^{1}$ Ashley N. Watson, ${ }^{1}$ and Andy Y. Shih ${ }^{1,2}$ \\ ${ }^{1}$ Department of Neurosciences and ${ }^{2}$ Center for Biomedical Imaging, Medical University of South Carolina, Charleston, South Carolina 29425
}

Blood-brain barrier disruption (BBB) and release of toxic blood molecules into the brain contributes to neuronal injury during stroke and other cerebrovascular diseases. While pericytes are builders and custodians of the BBB in the normal brain, their impact on BBB integrity during ischemia remains unclear. We imaged pericyte-labeled transgenic mice with in vivo two-photon microscopy to examine the relationship between pericytes and blood plasma leakage during photothrombotic occlusion of cortical capillaries. Upon cessation of capillary flow, we observed that plasma leakage occurred with three times greater frequency in regions where pericyte somata adjoined the endothelium. Pericyte somata covered only $7 \%$ of the total capillary length in cortex, indicating that a disproportionate amount of leakage occurred from a small fraction of the capillary bed. Plasma leakage was preceded by rapid activation of matrix metalloproteinase (MMP) at pericyte somata, which was visualized at high resolution in vivo using a fluorescent probe for matrix metalloproteinase-2/9 activity, fluorescein isothiocyanate (FITC)-gelatin. Coinjection of an MMP-9 inhibitor, but not an MMP-2 inhibitor, reduced pericyteassociated FITC-gelatin fluorescence and plasma leakage. These results suggest that pericytes contribute to rapid and localized proteolytic degradation of the BBB during cerebral ischemia.

Key words: blood-brain barrier; capillary; matrix-metalloproteinase; pericyte; stroke; two-photon imaging

Significance Statement

Pericytes are a key component of the neurovascular unit and are essential for normal BBB function. However, during acute ischemia, we find that pericytes are involved in creating rapid and heterogeneous BBB disruption in the capillary bed. The mechanism by which pericytes contribute to BBB damage warrants further investigation, as it may yield new therapeutic targets for acute stroke injury and other neurological diseases involving capillary flow impairment.

\section{Introduction}

The blood-brain barrier (BBB) is a highly selective vascular structure that prevents harmful blood-borne substances from entering the brain (Sandoval and Witt, 2008). Increased BBB permeability worsens stroke outcome by exposing neurons to blood components, increasing tissue edema (Larrue et al., 1997) and limiting the window for thrombolytic treatment (Hawkins and

Received Sept. 14, 2016; revised 0ct. 20, 2016; accepted Nov. 1, 2016.

Author contributions: R.G.U. and A.Y.S. designed research; R.G.U., M.L., D.A.H., R.I.G., A.N.W., and A.Y.S. performed research; R.G.U., D.A.H., R.I.G., A.N.W., and A.Y.S. analyzed data; R.G.U., M.L., D.A.H., R.I.G., A.N.W., and A.Y.S. wrote the paper.

This work is supported by Grants NS-085402 and NS-096997 to A.Y.S. from the National Institute of Neurological Disorders and Stroke (NINDS), the Dana Foundation, American Heart Association Grant 14GRNT20480366, South Carolina Clinical and Translational Institute Grant UL1TR000062, and an Institutional Development Award (IDeA) from the National Institute of General Medical Sciences under Grant P20-GM-12345. D.A.H. is supported by National Institutes of Health (NIH) Grant T32-GM-08716, NIH-NCATS Grants UL1-TR-001450 and TL1-TR-001451, and NIHNINDS Grant F30-NS-096868.

The authors declare no competing financial interests.

Correspondence should be addressed to Andy Y. Shih, Department of Neurosciences, Medical University of South Carolina, 173 Ashley Avenue, CRI 406, Charleston, SC 29425. E-mail: shiha@musc.edu.

DOI:10.1523/JNEUROSCI.2891-16.2016

Copyright $\odot 2017$ the authors $\quad 0270-6474 / 17 / 370129-12 \$ 15.00 / 0$
Davis, 2005; Desilles et al., 2013). Cerebral pericytes may play a role in BBB changes after stroke, as they are essential for the proper formation and maintenance of the BBB in the normal brain (Winkler et al., 2011; Liu et al., 2012). Their continuous signaling with the endothelium promotes normal tight junction development, and regulates vesicular trafficking and immune cell infiltration across the endothelium (Armulik et al., 2005; Daneman et al., 2010; Ben-Zvi et al., 2014). An inability to recruit pericytes to the endothelium in embryonic lethal PDGFB or platelet-derived growth factor receptor $\beta$ (PDGFR $\beta$ ) knock-out mice results in severe vascular abnormalities (Hellström et al., 1999), plasma leakage, and microaneurysm formation (Lindahl et al., 1997). A partial congenital loss of PDGFR $\beta$ signaling allows animals to survive to adulthood, but progressive BBB impairments increase with age, resulting in neural dysfunction and cognitive decline (Bell et al., 2010). Perturbation of pericyte signaling during adulthood results in increased endothelial transcytosis, indicating that pericytes maintain BBB function even after stable integration into the vasculature (Armulik et al., 2010). Furthermore, a polymorphism in the Foxf2 gene, which is physiologically important for pericyte regulation of the BBB (Reyahi et al., 2015), 
increases the risk of stroke in humans (Neurology Working Group of the Cohorts for Heart and Aging Research in Genomic Epidemiology Consortium, Stroke Genetics Network, International Stroke Genetics Consortium, 2016).

While BBB dysfunction caused by genetically induced defects in pericyte signaling has been well studied, it is less clear how normally developed pericytes in the adult brain respond to acute ischemia. Early ultrastructural studies have shown that some pericytes migrate from the endothelium during ischemia and traumatic brain injury (Takahashi et al., 1997; Dore-Duffy et al., 2000; Duz et al., 2007). More recent work has suggested that capillary pericytes die earlier than other cells of the neurovascular unit during stroke (Hall et al., 2014). The most well studied aspect of this vulnerability is the effect of the aberrant contraction of pericytes (or closely related smooth muscle cells), which can influence capillary diameter and the quality of cerebral blood flow during reperfusion (Peppiatt et al., 2006; Yemisci et al., 2009; Fernández-Klett et al., 2010; Hall et al., 2014; Hill et al., 2015; Attwell et al., 2016). However, another consequence of early pericyte death could be BBB disruption, which is relatively unexplored. Cultured pericytes have recently been shown to produce matrix metalloproteinases (MMPs; Thanabalasundaram et al., 2011; Takahashi et al., 2014), which are key mediators of BBB disruption during stroke (Yang et al., 2007; Barr et al., 2010) and during small-vessel disease in dementia (Weekman and Wilcock, 2015). In particular, various inflammatory signaling cascades can induce pericyte MMP-9 expression in vitro (Takata et al., 2011; Machida et al., 2015) and in vivo (Gurney et al., 2006; Bell et al., 2012). This suggests that, unlike their supportive roles during normal brain function, pericytes may open a route for vascular leakage by enhancing MMP activity during ischemia.

Here, we used in vivo two-photon microscopy to study the relationship among pericytes, MMP activity, and BBB leakage during ischemia within the cortical capillary bed (Shih et al., 2013; Taylor et al., 2016). We occluded a small region of the capillary bed by photothrombosis to better preserve imaging quality. We further imaged transgenic mouse lines expressing fluorescent reporters specifically in pericytes to unambiguously identify these structurally elaborate cells and their ovoid-shaped somata (Hartmann et al., 2015). Finally, we used a fluorescein isothiocyanate (FITC)-conjugated gelatin probe to detect gelatinase activity (MMP-2/9) in vivo with high spatiotemporal resolution. Our findings show that ischemia results in rapid (tens of minutes) and localized activation of MMP-9 and plasma leakage, preferentially where pericyte somata adjoin the capillary wall. These results provide strong evidence that pericytes are contributors to early BBB degradation during ischemia.

\section{Materials and Methods}

Mice. tdTomato reporter mice (Ai14) on a C57BL/6 background were purchased from The Jackson Laboratory (stock \#007914; Madisen et al., 2010). These mice were bred with the following two different Cre driver lines to achieve transgene expression in pericytes: PDGFR $\beta$ Cre mice (a gift from Volkhard Lindner, Maine Medical Center Research Institute, Portland, Maine; Cuttler et al., 2011) and neural/glial antigen 2 (NG2)-CreER mice (stock \#008538, The Jackson Laboratory; Zhu et al., 2011). Mice were maintained in standard cages on a $12 \mathrm{~h} \mathrm{light/dark} \mathrm{cycle,} \mathrm{and} \mathrm{housed} \mathrm{five} \mathrm{or} \mathrm{fewer} \mathrm{per} \mathrm{cage.} \mathrm{Following} \mathrm{any}$ surgical procedure, mice were housed singly. Both male and female mice were used, and all mice used were between 2 and 5 months of age. To induce transgene expression in NG2-CreER mice, tamoxifen dissolved in corn oil/ethanol (9:1) was injected intraperitoneally at a dose of $100 \mathrm{mg} / \mathrm{kg}$, every $24 \mathrm{~h}$ for 5 consecutive days (Madisen et al.,
2010). These mice were then imaged within 2 weeks after the final tamoxifen injection.

Surgery. Polished and reinforced thinned-skull windows (Shih et al., 2012) or skull-removed, dura-intact craniotomies (Mostany and Portera-Cailliau, 2008) were generated over the sensorimotor cortex to achieve optical access for two-photon imaging. When intracortical injections of FITC-gelatin and other drugs were required (see below), craniotomies were generated, and animals were imaged immediately after sealing the craniotomy with a coverslip. Otherwise, imaging was conducted the day after polished and reinforced thinned-skull window generation. Anesthesia was induced with isoflurane (Patterson Veterinary) at $3 \%$ mean alveolar concentration in $100 \%$ oxygen (AirGas) and maintained at $1-2 \%$ during surgery. Body temperature was maintained at $37^{\circ} \mathrm{C}$ with a feedback-regulated heat pad. All animals were administered buprenorphine for analgesia before surgery at a concentration of 0.025 $\mathrm{mg} / \mathrm{kg}$. These procedures were approved by the Institutional Animal Care and Use Committee at the Medical University of South Carolina.

In vivo two-photon microscopy. Two-photon imaging was performed with a Sutter Moveable Objective Microscope and a Coherent Ultra II Ti:Sapphire laser source. Excitation was $975 \mathrm{~nm}$ for imaging FITCdextran and tdTomato. Excitation was $800 \mathrm{~nm}$ for experiments involving FITC-gelatin and Texas red-dextran. In the latter case, excitation was tuned to $975 \mathrm{~nm}$ to capture tdTomato fluorescence at the start of each experiment. Green and red emission was simultaneously collected using ET525/70m and ET605/70m filter sets, respectively (Chroma). Throughout the duration of imaging, mice were maintained under light isoflurane $(0.75 \%)$ supplied in medical air $(20-22 \%$ oxygen and $78 \%$ nitrogen, moisturized by bubbling through water; AirGas). Pulse oximetry (MouseOx, Starr Life Sciences) was used to monitor blood oxygen saturation and heart rate to ensure that cardiovascular function was normal during imaging.

Procedures for blood flow imaging and analysis have been described previously (Shih et al., 2012). Briefly, the blood serum was labeled by an infraorbital vein injection of $0.025 \mathrm{ml}$ of FITC-dextran (2 MDa; FD2000S Sigma-Aldrich) or Texas red-dextran (70 kDa; D-1830, Life Technologies) prepared at a concentration of $5 \%(\mathrm{w} / \mathrm{v})$ in sterile saline. A $4 \times, 0.13$ numerical aperture (NA) air-objective lens (UPLFLN $4 \times$, Olympus) was used to generate vascular maps of the entire window for navigational purposes. High-resolution imaging was performed using a waterimmersion 20×, 1.0 NA objective lens (XLUMPLFLN 20XW, Olympus). Tissue volumes sampled at high resolution were $211 \times 211 \times 150 \mu \mathrm{m}$ in the $x$-, $y$-, and $z$-planes, respectively. Lateral sampling $(x, y)$ was 0.41 $\mu \mathrm{m} /$ pixel, and axial sampling $(z)$ was $1 \mu \mathrm{m} /$ pixel.

Photothrombotic occlusions. For restricted photothrombotic occlusion of capillaries, a focused green laser $(1 \mathrm{~mW}, 20 \mu \mathrm{m}$ diameter at the focal plane) was applied directly to the superficial capillary bed (avoiding pericyte somata), immediately following a retro-orbital vein injection of $\sim 25-50 \mu$ l of Rose Bengal, prepared at $1.25 \%(\mathrm{w} / \mathrm{v})$ in sterile saline. This led to diffuse irradiation of surrounding capillaries, resulting in the loss of capillary flow and gradual BBB leakage. We titrated the extent of capillary occlusion by modifying the duration of irradiation while keeping intravenous Rose Bengal dose fixed. The experiments in this study involved a 25 s green laser irradiation. On rare occlusions ( 2 of 56 occlusions), the photothrombosis led to immediate BBB damage ( $<5$ min postocclusion), likely due to damage of a larger venule or arteriole. These data were omitted from the analyses.

Quantification of capillary leakage sites. Vascular leakage was quantified from 3D renderings of the FITC-dextran-labeled green channel using Imaris 7.7 software (Bitplane), and also confirmed in twodimensional images by scrolling through two-photon image stacks with Fiji software. Leakage events were defined as the localized permeation of FITC-dextran from the intravascular space into the surrounding parenchyma. Leakage sites typically possessed an intensely fluorescent focus surrounded by a more diffuse cloud of fluorescence. The position of the leakage focus was first established by visual inspection, and then the second, tdTomato-positive imaging channel was used to determine its position relative to a pericyte soma. To be counted as a soma-specific event, the focus of the leakage site needed to be within $3 \mu \mathrm{m}$ from the edge of a pericyte soma at its first obser- 

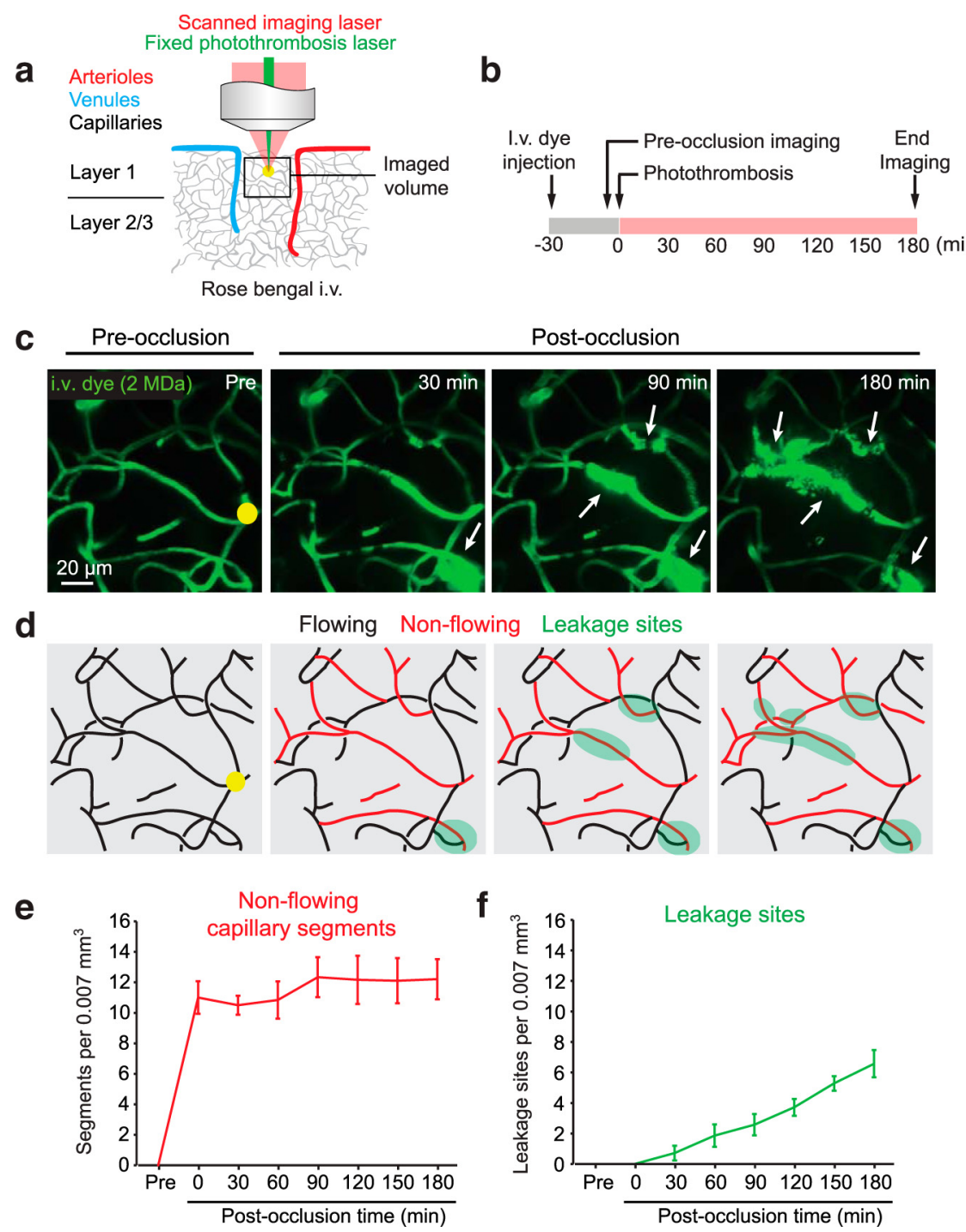

Figure 1. Induction of capillary ischemia during two-photon imaging. $\boldsymbol{a}$, Schematic demonstrating the imaged tissue volume. Focal photothrombotic irradiations were directed at the capillary bed to generate restricted regions of capillary ischemia. $\boldsymbol{b}$, Experimental time course for imaging of vascular leakage after photothrombosis. c, Progression of capillary intravenous dye (FITC-dextran) leakage following photothrombosis. The focal point of the green photothrombosis laser is marked with a yellow circle. White arrows correspond to leakage sites. $\boldsymbol{d}$, Schematized vascular map from c to show capillaries with red blood cell flow (black) or without flow (red). Regions of intravenous dye leakage are shown in green. $\boldsymbol{e}$, Mean number of nonflowing capillary segments over the experimental time course. The zero time point is collected immediately following occlusion. $\boldsymbol{f}$, Mean number of leakage sites occurring within the imaging field over the experimental time course. $N=18$ occlusion sites over 10 mice for both $\boldsymbol{e}$ and $\boldsymbol{f}$. The number of capillary segments or leakage sites is counted within the sampled tissue volume, $0.007 \mathrm{~mm}^{3}$. Data are shown as the mean $\pm \mathrm{SEM}$.

vation following photothrombosis. This offered a $\sim 5 \%$ error margin on either side of a pericyte soma, considering that the median length of capillary segments in cortex is $50 \mu \mathrm{m}$ (Blinder et al., 2013). At each imaging time point, leakage sites associated with a pericyte soma (pericyte) or not associated with one (nonpericyte) were counted to obtain a cumulative tally over time for each site of photothrombotic irradiation. The rate of leakage site formation was then determined for pericyte soma and nonpericyte groups by performing a linear regression of the time course data and calculating the slope of the fit.

In a subset of leakage events, we quantified the spatial extent of capillary leakage plumes. These analyses were performed on 3-D renderings of the FITC-dextran-labeled channel (see Fig. 2. A string of 16 regions of interest (ROIs; with dimensions $8 \times 8 \times 16 \mu \mathrm{m}$ in the $x$-, $y$-, and $z$-planes, respectively) were placed along the capillary of interest, and the volume of FITC in each ROI was measured before and after ischemia. Regardless of the position of pericyte somata, the ROI with the highest FITC-dextran volume after occlusion was centered at ROI 8. If a tdTomato-positive pericyte soma partially resided within the central ROIs (ROIs 7-9), the leakage site was categorized as a pericyte soma- specific leakage event. All other cases were categorized as nonpericyte soma events.

In vivo gelatin zymography. An FITC-gelatin probe (Bozdagi et al., 2007; DQ-Gelatin, D12054, Life Technologies), diluted to a concentration of $1 \mathrm{mg} / \mathrm{ml}$ in sterile PBS, was pressure injected into the cortex using a pulled glass pipette $(10-20 \mu \mathrm{m}$ tip diameter). The pipette tip was lowered $250 \mu \mathrm{m}$ into the cortex with a Sutter MP-285 manipulator following the removal of a circular portion of skull $(\sim 2 \mathrm{~mm})$ over the somatosensory area. A small excision was made in the dura mater using a 26 gauge syringe needle tip for entry of the glass pipette. FITC-gelatin was injected over 5 min using a Picospritzer ( $10-20$ ms pulses, 5-15 psi, 0.5-2 $\mathrm{Hz}$ pulse frequency) until $200 \mathrm{nl}$ was delivered. The injection pipette was then left in place for $10 \mathrm{~min}$ before removal from the cortex. The craniotomy was then overlaid with $1.5 \%$ agarose followed by a circular coverslip. The coverslip was fixed in position with dental cement before two-photon imaging.

FITC-gelatin-labeled cells were quantified in image stacks using Fiji software. Cell bodies that were positive for FITC-gelatin were defined as cells with $35 \%$ greater fluorescence intensity than the surrounding neuropil. Cells that colocalized with pericyte somata (tdTomato) were 
a

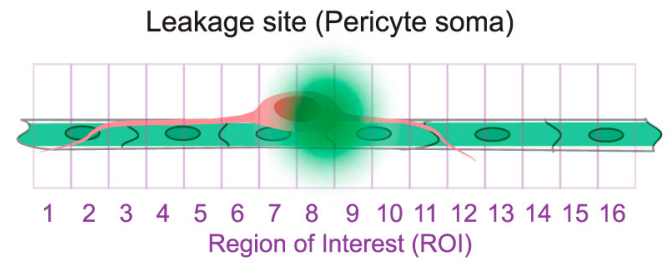

b
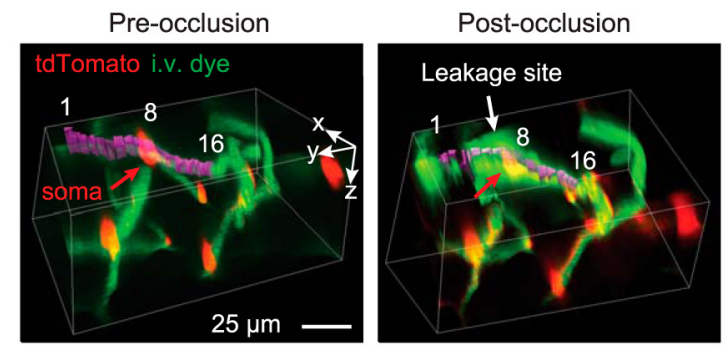

C

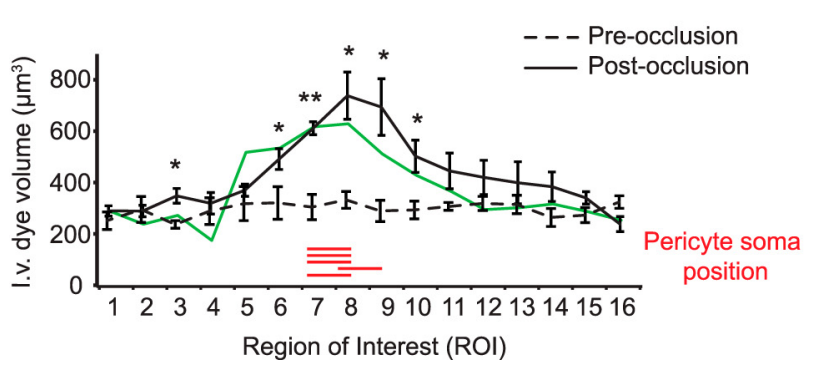

d Leakage site (No pericyte soma)

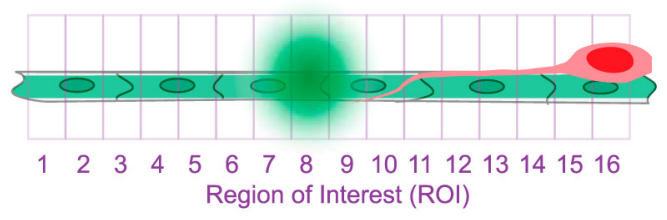

e
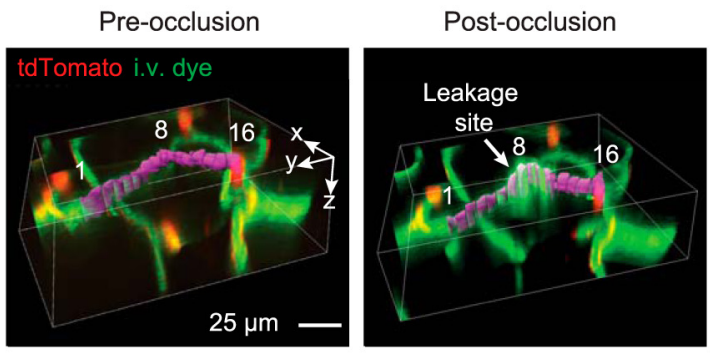

f

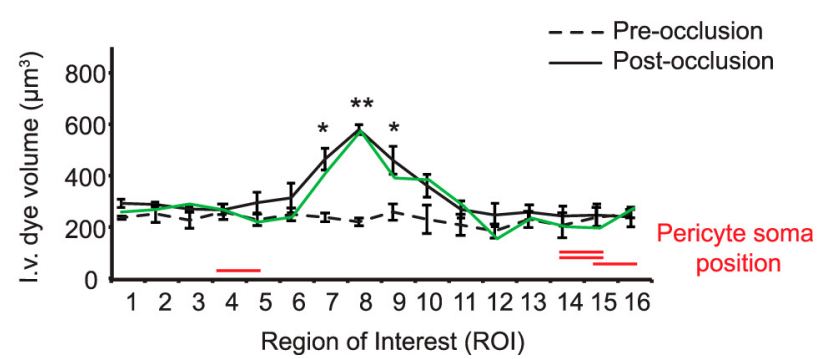

Figure 2. Spatial profile of capillary leakage at pericyte soma and nonsoma locations. $\boldsymbol{a}$, Schematic showing leakage site occurring at a pericyte soma and 16 ROIs used for the quantification in c. ROI dimensions were $8 \times 8 \times 16 \mu \mathrm{m}$ in the $x-, y$-, and $z$-planes. The ROl of greatest leakage volume was placed at the central ROI (ROI 8). $\boldsymbol{b}$, Representative 3-D renderings of intravenous dye extravasation at a pericyte soma (red arrow). ROls (purple, showing actual volume occupied by intravenous dye) were strung along the capillary segment to quantify the volume of dye at preocclusion and $30 \mathrm{~min}$ postocclusion. The site of plasma leakage is shown with a white arrow. c, Mean intravenous dye volume per ROI for five pericyte soma leakage sites (over three mice). The location of the pericyte somata, from the tdTomato channel, corresponds with the ROls with the greatest volume of extravasated dye. The green trace is data from the specific leakage site shown in $\boldsymbol{b}$. ${ }^{*} p<0.05$ and $^{* *} p<0.01$ denote a significant volume increase from preocclusion values for the same $\mathrm{ROI}$; multiple paired $t$ tests. $\mathrm{ROI} 3, p=0.033 ; \mathrm{ROI} 6, p=0.012 ; \mathrm{ROI} 7, p=0.003 ; \mathrm{ROI} 8, p=0.012 ; \mathrm{ROI}$ $9, p=0.019 ; \mathrm{ROI} 10, p=0.035$. Data are shown as the mean \pm SEM. $\boldsymbol{d}-\boldsymbol{f}$, Equivalent analyses shown in panels ( $\boldsymbol{a}-\boldsymbol{c}$ ) for five leakage sites (over three mice) occurring in the absence of a pericyte soma. In $\boldsymbol{f}$, pericyte somata for four of five cases were present in the sampled regions, but the positions of these somata were not correlated with the peak leakage volume. ${ }^{*} p<0.05$ and ${ }^{* *} p<$ 0.01 denote a significant volume increase from preocclusion values for the same ROl; multiple paired $t$ tests. $\mathrm{ROI} 1, p=0.031 ; \mathrm{ROI} 7, p=0.015 ; \mathrm{R} 018, p=0.001 ; \mathrm{ROI} 9, p=0.042$. Data shown as the mean $\pm S E M$.

counted as FITC-gelatin-positive pericytes. Areas of heightened FITC fluorescence that did not colocalize with pericyte somata, but exhibited some cellular morphology, were counted as FITC-gelatin-positive nonpericytes (see Figs. 5, 6). For studies using MMP-9 knock-out mice (stock \#007084, The Jackson Laboratory) and C57BL/6 controls (stock \#000664, The Jackson Laboratory), two-photon image stacks covering a $7 \mu \mathrm{m}$ thickness $\sim 75 \mu \mathrm{m}$ below the pia were maximally projected. The fluorescence intensity across the entire image field was quantified using Fiji software with no discrimination for specific cell types.

Matrix metalloproteinase inhibition: systemic administration. GM6001 and SB-3CT were administered intraperitoneally at concentrations of $100 \mathrm{mg} / \mathrm{kg}$ (Lee et al., 2006) and $25 \mathrm{mg} / \mathrm{kg}$ (Gu et al., 2005), respectively. Both compounds were first dissolved in pure dimethylsulfoxide (DMSO), and then polyethylene glycol (PEG) and PBS were added to complete the vehicle (38\% DMSO, 31\% PEG, 31\% PBS). Since a high level of DMSO was required to completely dissolve the compounds, we also included a vehicle-only injection group.

Intracortical injections. Isoform-specific inhibitors of gelatinases were coinjected with FITC-gelatin since their ability to pass the BBB has not been studied in detail. These included the MMP-2 inhibitor oleoyl- $N$ hydroxylamide (catalog \#444244, EMD Millipore; MMP-2, inhibitory constant $\left(K_{\mathrm{i}}\right)=1.07 \mu \mathrm{M}$; MMP-9, $K_{\mathrm{i}}>50 \mu \mathrm{M}$,), and MMP-9 inhibitor $\mathrm{C}_{27} \mathrm{H}_{33} \mathrm{~N}_{3} \mathrm{O}_{5} \mathrm{~S}$ (catalog \#444278, EMD Millipore; MMP-9, $K_{\mathrm{i}}=5 \mathrm{nM}$; MMP-1, $K_{\mathrm{i}}=1.05 \mathrm{~mm}$; and MMP-13, $K_{\mathrm{i}}=113 \mathrm{~nm}$; Smith et al., 2014). Both compounds were first dissolved in pure DMSO and then diluted to working concentrations in $1 \mathrm{mg} / \mathrm{ml}$ FITC-gelatin in PBS. A total of 5 pmol MMP-2 inhibitor or 0.02 pmol MMP-9 inhibitor was injected per animal. These amounts were calculated to be $\sim 20$ times above the $K_{\mathrm{i}}$ for the target isoform, to account for dilution once injected into the cortex, but were well below brain concentrations that could nonspecifically affect other MMP isoforms. All imaging studies were performed within the first 2-3 h following drug injection. A vehicle injection group was not included for intracortical injection experiments because the final DMSO concentration was negligible $(0.24 \% \mathrm{v} / \mathrm{v})$. No animals died as a result of drug administration in these studies. While no randomization of animals was used during data collection, the analyses were performed with the rater blinded to treatment groups.

Statistics. All statistical analyses were performed using custom code written with MATLAB or SPSS software. Statistical details are provided in the legend of each figure. Our sample size is similar to those of previously reported studies using related techniques (Shih et al., 2013; Taylor et al., 2016). The normality of datasets was examined using the Lilliefors test to decide upon the use of parametric or nonparametric analyses.

\section{Results}

Induction of capillary ischemia in mouse cortex using targeted photothrombosis

We established a highly reproducible model of capillary ischemia by inducing photothrombotic occlusion of superficial cortical capillaries in vivo (Fig. 1a). A high-molecular weight fluorescent dye (2 MDa FITC-dextran) was first intravenously injected to 
a

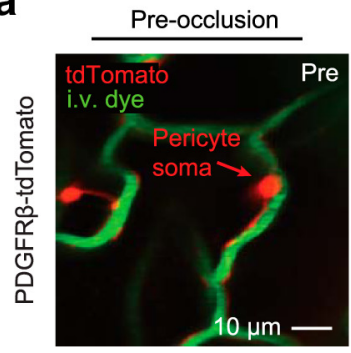

b

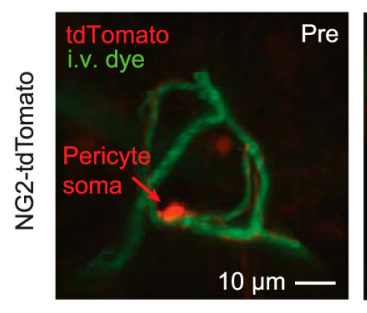

Post-occlusion
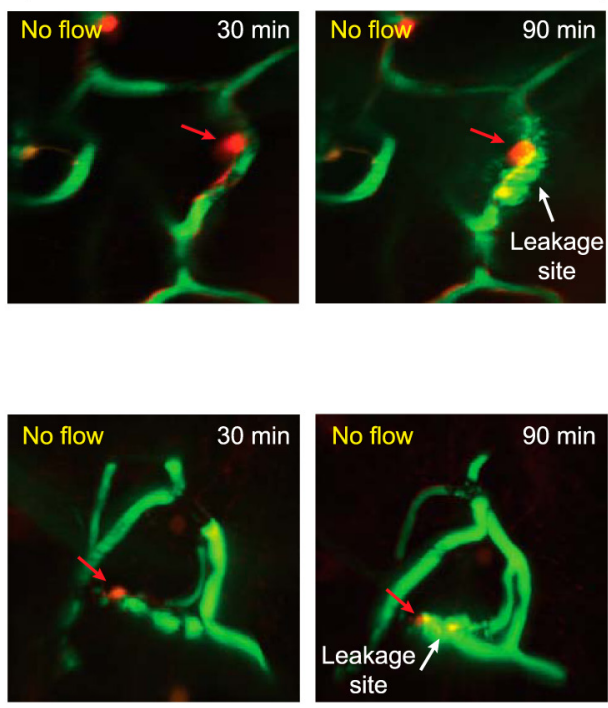

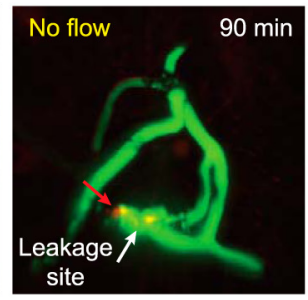

C

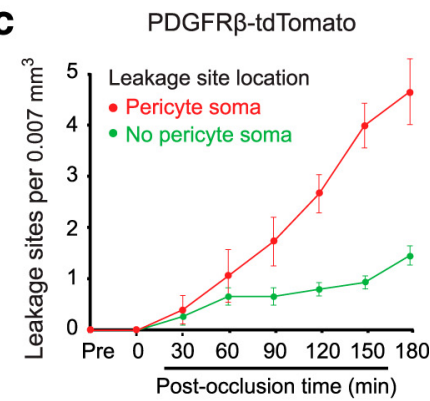

d

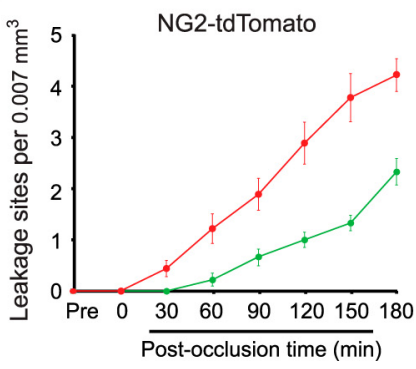

Figure 3. Capillary leakage sites occur preferentially at pericyte somata. $\boldsymbol{a}, \boldsymbol{b}$, Representative high-resolution examples of capillary leakage occurring at the pericyte soma. Leakage is observed with both PDGFR $\beta$-tdTomato $(\boldsymbol{a})$ and NG2-tdTomato $(\boldsymbol{b})$ mice. The locations of pericyte somata are marked with red arrows, while the first observation of local intravenous dye leakage is marked with white arrows. Images are maximal projections over $\sim 15 \mu \mathrm{m}$ of tissue. $\boldsymbol{c}, \boldsymbol{d}$, Mean number of leakage sites occurring at the pericyte soma, versus regions with no pericyte soma, plotted as a function of time. $p<0.001$ (main effect), $F_{(2.87,34.45)}=18.553$ for PDGFR $\beta$-tdTomato $\left(n=7\right.$ occlusion sites over four mice), and $p<0.001$ (main effect), $F_{(2.35,37.66)}=9.343$ for NG2-tdTomato ( $n=11$ occlusion sites over six mice); two-way ANOVA with repeated-measures with Greenehouse-Geisser correction. Data are shown as the mean \pm SEM.

label the blood plasma for imaging. Following a subsequent intravenous injection of the photosensitizing agent Rose Bengal, the cortical surface was briefly irradiated with a focused green laser. The evolution of capillary flow and leakage was then tracked with two-photon microscopy over a period of $3 \mathrm{~h}$ (Fig. $1 b, c)$. The irradiation led to the immediate cessation of flow in a subset of capillaries within the imaging field $(\sim 10$ nonflowing capillary segments in a $0.007 \mathrm{~mm}^{3}$ imaging volume containing 20 total capillary segments, where "segment" is defined as a capillary region between two branch points), and the majority of these capillaries remained nonflowing for the duration of imaging (Fig. 1d,e, red lines). Within 30 min postonset, we observed deterioration of the $\mathrm{BBB}$, which manifested as extravasation of the fluorescent intravenous dye (Fig. $1 c, d, f$ ). We noted that leakage was heightened in small regions along the capillary, spanning $10-40 \mu \mathrm{m}$ in length, despite the loss of flow through entire capillary segments that were typically $50-100 \mu \mathrm{m}$ in length. Leakage occurred only in capillaries experiencing complete cessation of blood flow ( $0 \%$ of 56 flowing segments, and $60 \%$ of 39 nonflowing segments within the same imaged tissue volume). This suggested that localized BBB leakage was an effect of capillary ischemia, rather than nonspecific actions of phototoxicity or oxidative injury, which would have similarly affected flowing capillaries (Fig. 1d, black lines). We performed initial studies with a high-molecular weight dextran $(2 \mathrm{MDa})$, which diffused more slowly and allowed the initial sites of extravasation to be better discerned (Chen et al., 2009). However, subsequent studies showed similar leakage with a $70 \mathrm{kDa}$ Texas red-dextran, indicating extravasation of smaller blood components as well.

\section{Plasma leakage emerges preferentially at pericyte somata}

We examined the spatial relationship between localized capillary leakage and the position of pericyte somata, which were visible in a second channel when imaging PDGFR $\beta$-tdTomato mice (Fig. 2). The leakage sites typically possessed an intensely fluorescent focus surrounded by a more diffuse cloud of fluorescence. We observed leakage sites closely associated with pericyte somata as well as sites away from pericyte somata. These events were categorized as pericyte specific or non-pericyte specific, based on the localization of the somata to the focus of the plasma leakage plume (see Materials and Methods). To confirm that our visual inspection truly captured this dichotomy, we used a series of adjacent ROIs strung along a subset of capillaries to measure the volume of extravasated intravenous dye relative to the pericyte soma (Fig. 2a,b). These data confirmed that, in many cases, the ROI with the greatest dye extravasation volume overlapped directly with the location of the pericyte soma (Fig. $2 a-c$ ). At leakage sites not associated with pericyte somata, the dye extravasation profile was similar to pericyte soma leakage sites (Fig. $2 d-f)$.

We next quantified the relative abundance of leakage sites occurring at pericyte soma versus nonsoma locations (Fig. 3). Over a $3 \mathrm{~h}$ postocclusion period, pericyte soma leakage sites developed at approximately three times the rate of nonsoma leakage sites (i.e., $\sim 80 \%$ of all leakage sites observed; Fig. $3 a, c$ ). A similar effect was observed in another pericyte-labeled mouse line, NG2-tdTomato (Fig. 3b,d). Using cortical vascular reconstructions from PDGFR $\beta$-tdTomato mice (Hartmann et al., 2015), we determined that only $7.1 \pm 0.4 \%$ (mean \pm SD) of the total capillary length was in contact with pericyte somata, while the remainder was covered by the extensive pericyte processes (105 $\mathrm{mm}$ of total capillary length examined from $n=3$ mice). Thus, a disproportionate number of leakage sites were occurring in a restricted fraction of the capillary bed where pericyte somata were located. 


\section{a}

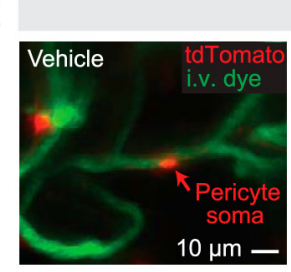

b

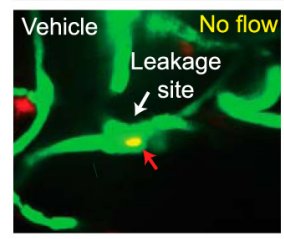

C

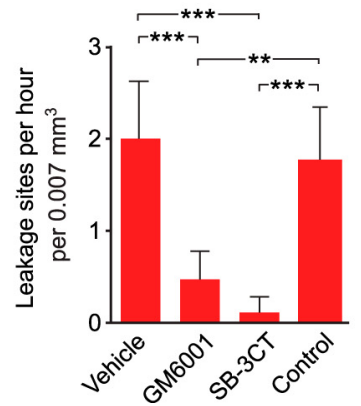

Pre-occlusion
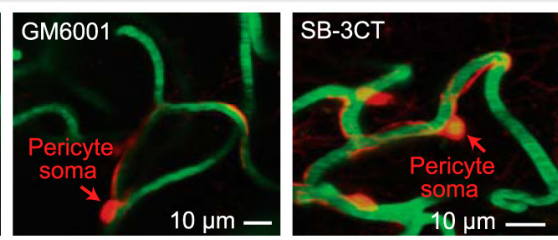

Post-occlusion (90 min)
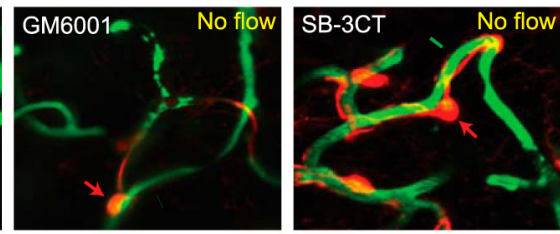

d

No pericyte soma

e

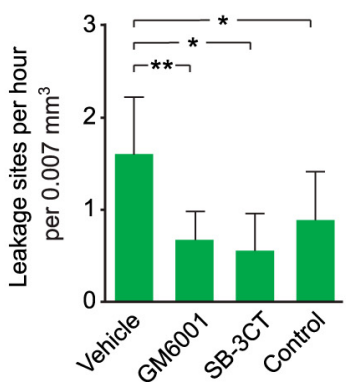

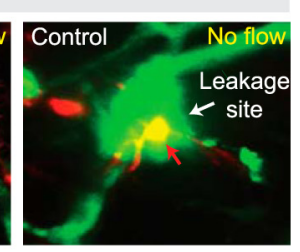

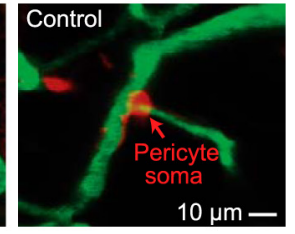

$10 \mu \mathrm{m}-$

Non-flowing capillaries

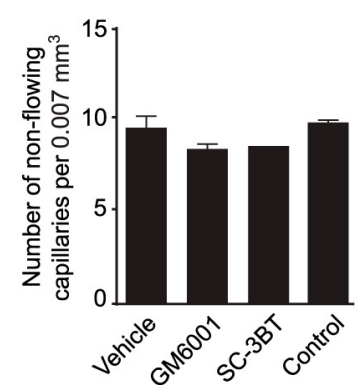

Figure 4. Systemic administration of MMP inhibitors attenuates leakage occurring at pericyte somata. $\boldsymbol{a}, \boldsymbol{b}$, Representative examples of capillaries before and 90 min following photothrombosis with various treatment groups. These studies were performed with NG2-tdTomato mice. Mice were intraperitoneally injected with a broad-spectrum MMP inhibitor, GM6001, or an MMP 2/9-specific inhibitor, SB-3CT, and compared with vehicle-treated or nontreated controls. Data for the control group are equivalent to those of the NG2-tdTomato data shown in Figure 3d. The locations of pericyte somata are marked with red arrows. The first observation of leakage sites is marked with a white arrow. c, Summary for rate of leakage site formation in various treatment groups occurring at pericyte somata. $p<0.001$ (main effect); ${ }^{* * *} p<0.001$ (vehicle vs GM6001); ${ }^{* * *} p<0.001$ (vehicle vs SB-3CT); ${ }^{* *} p<0.01$ (control vs GM6001); ${ }^{* * *} p<0.001$ (control vs SB-3CT); $p=0.22$ (vehicle vs control); $p=0.67$ (GM6001 vs SB-3CT); $F_{(7,68)}=12.993$; one-way ANOVA with Tukey's HSD post hoc test $(n=7$ occlusion sites over four mice for vehicle; $n=11$ occlusion sites over six mice for control; $n=7$ occlusion sites over five mice for GM6001; and $n=12$ occlusion sites over four mice for SB-3CT). Data are shown as the mean \pm SEM. $\boldsymbol{d}$, Summary for the rate of leakage events occurring at nonpericyte soma locations. $p<0.001$ (main effect); ${ }^{* *} p<0.01$ (vehicle vs GM6001); $p<0.05$ (vehicle vs SB-3CT); $p=1.00$ (control vs GM6001); $p=1.00$ (control vs SB-3CT); ${ }^{*} p<$ 0.05 (vehicle vs control); $p=0.41$ (GM6001 vs SB-3CT); $F_{(7,68)}=12.993$; one-way ANOVA with Tukey's HSD post hoc test. Data are shown as the mean \pm SEM. $\boldsymbol{e}$, The average number of nonflowing capillary segments generated by photothrombosis, examined at 120 min postocclusion, was not different between treatment groups. $p=0.61$; one-way ANOVA. Data are shown as the mean \pm SEM.

\section{Pericyte soma-specific capillary leakage is dependent on gelatinase activity}

To determine whether MMP activity was involved in capillary leakage at pericyte somata, we administered small-molecule inhibitors of MMPs intraperitoneally $30 \mathrm{~min}$ before photothrombosis. We used GM6001 (Lee et al., 2006) to block MMPs broadly or SB-3CT (Gu et al., 2005) to inhibit the gelatinase isoforms MMP-9 and MMP-2 (Fig. 4). Both inhibitors effectively attenuated the formation of leakage events at pericyte somata compared with untreated controls (Fig. 4a-c). MMP inhibitors did not significantly affect the number of leakage sites occurring in the absence of a pericyte soma (Fig. 4d). We also treated animals with vehicle only (DMSO, PBS, and PEG) to control for the effects of DMSO, which was necessary to dissolve the inhibitors. Dimethylsulfoxide has been reported to exacerbate BBB leakage (Broadwell et al., 1982), and, consistent with this, the rate at which leakage events formed increased slightly or trended toward increase at both pericyte soma and nonsoma locations compared with untreated controls (Fig. $4 c, d$ ). Nevertheless, the MMP inhibitors were able to overcome leakage at pericyte somata induced by both ischemia and the vehicle. Critically, MMP inhibitors had no impact on the blockade of capillary flow by photothrombosis (Fig. 4e).

\section{In vivo high-resolution two-photon imaging of gelatinase activity}

To better understand the relationship between gelatinase activity and pericyte-specific leakage, we next performed in vivo gelatin zymography in PDGFR $\beta$-tdTomato mice using twophoton microscopy (Bozdagi et al., 2007; Garcia-Alloza et al., 2009; Bell et al., 2012). To observe FITC-gelatin activation in the capillary bed, we pressure injected a FITC-gelatin probe into the cortex before sealing the cranial window (Fig. 5a,b). On proteolytic cleavage by either MMP-2 or MMP-9, the FITC-gelatin fragments increase in fluorescence, allowing the detection of gelatinase activity with high spatiotemporal precision. Consistent with its sensitivity to gelatinase activity in vivo, basal FITC-gelatin fluorescence throughout the imaging field was reduced by $43 \pm 9 \%$ in MMP- 9 knock-out mice, compared with C57BL/6 controls $(n=3$ for both MMP-9 knock-out and C57BL/ 6 groups; $p<0.05, t$ test).

We next examined FITC-gelatin fluorescence changes at the cellular level in PDGFR $\beta$-tdTomato mice. Since FITC-gelatin cleavage was irreversible, we could observe an accumulation of fluorescence at cell bodies with heightened MMP-2/9 activity. FITC-gelatin-labeled cell bodies were categorized as either pericytes (tdTomato-positive) or nonpericytes (tdTomato-negative). We 
a

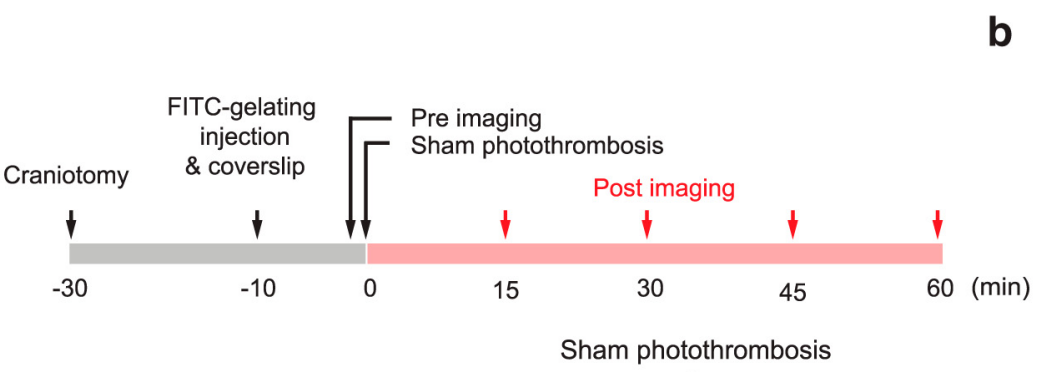

C
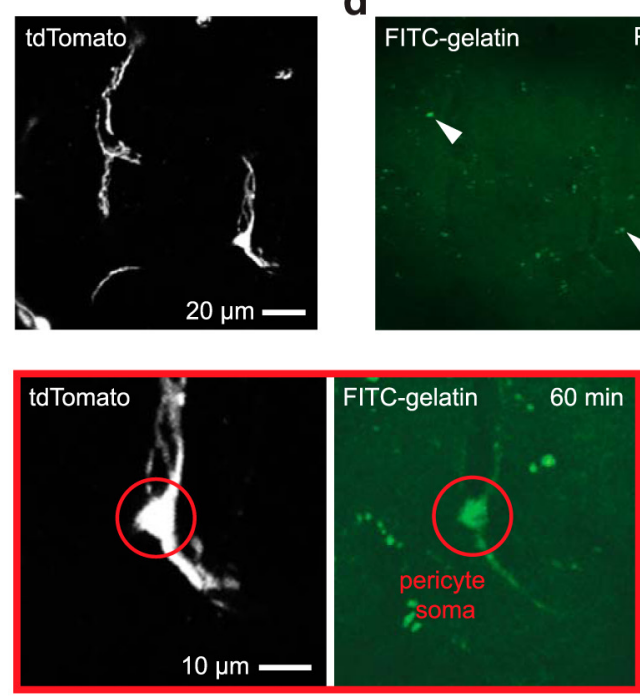

b

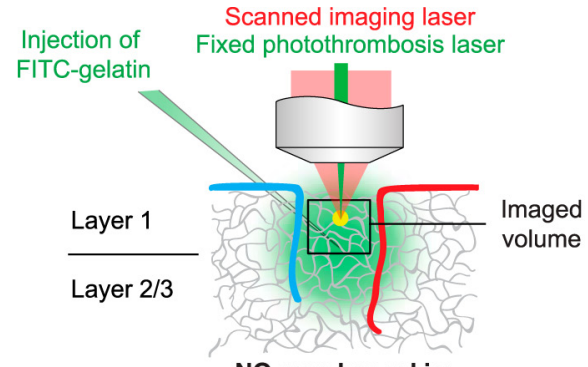

NO rose bengal i.v. d

Sham photothrombosis
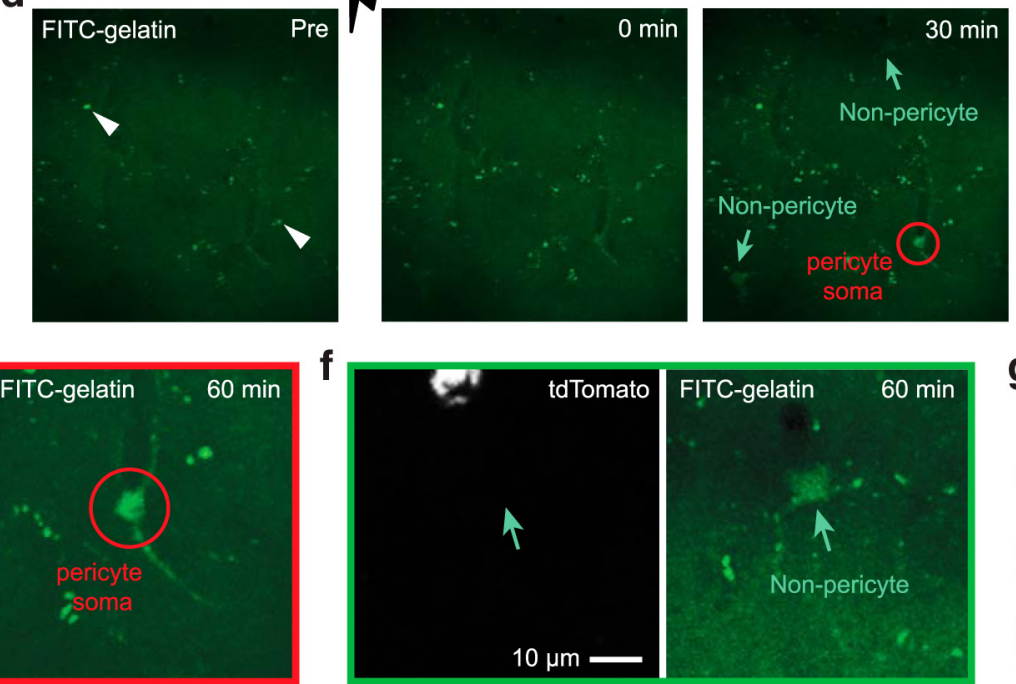

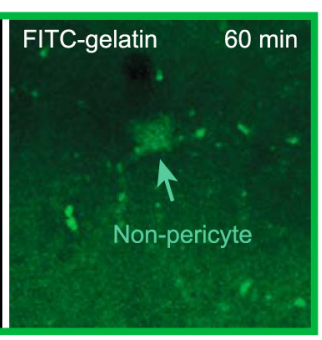

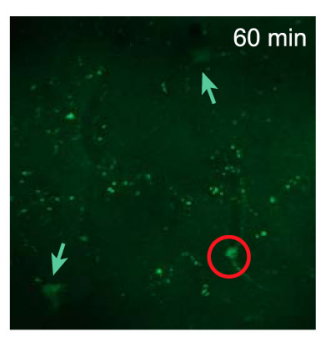

g

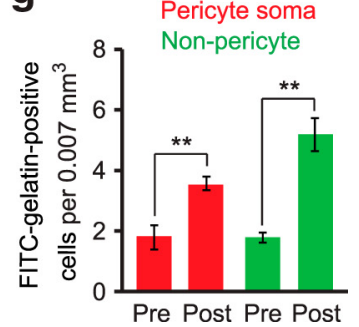

Figure 5. In vivo imaging of FITC-gelatin activation following sham irradiation. $\boldsymbol{a}$, Experimental time course for intracortical injection of FITC-gelatin and in vivo imaging. $\boldsymbol{b}$, Schematic showing the pressure injection of FITC-gelatin into cortex, and subsequent imaging. Sham irradiation involves exposure to focused green laser light, but no intravenous injection of Rose Bengal. $\boldsymbol{c}, \boldsymbol{d}$, Representative two-photon images demonstrating pericyte location (c) and the change in FITC-gelatin fluorescence $(\boldsymbol{d})$ following sham irradiation. White arrowheads show examples of bright puncta that may correspond to synaptic gelatinase activity. The red circle indicates an FITC-gelatin-positive pericyte soma, which colocalizes with tdTomato signal. The green arrows indicate the location of FITC-gelatin-positive cells that were not colocalized with tdTomato (nonpericytes). Images are maximal projections over $\sim 15 \mu$ m of tissue.e, Magnified view of the FITC-gelatin-positive pericyte soma (red circle in $\boldsymbol{d}, 60 \mathrm{~min}$ ). $\boldsymbol{f}$, Magnified view of a FITC-gelatin-positive nonpericyte (top green arrow in $\boldsymbol{d}, 60 \mathrm{~min}$ ). $\boldsymbol{g}$, Mean number of FITC-gelatin-positive pericytes (red) and nonpericyte cells (green) before and 60 min after sham irradiation. Paired-samples $t$ tests. ${ }^{* *} p<0.01$ ( $n=6$ occlusion sites over four mice). Data are shown as the mean \pm SEM.

present these results by first describing the evolution of FITCgelatin activation following control sham irradiation (Fig. 5) and photothrombotically induced capillary ischemia (Fig. 6). We then describe the relationship between FITC-gelatin activation and plasma leakage occurring at pericyte somata (Fig. 7) and away from pericyte somata (Fig. 8).

Before sham irradiation, the cortex emitted a homogeneous fluorescence from the neuropil. Scattered throughout the neuropil were brightly labeled puncta (1-2 $\mu \mathrm{m}$ in diameter) that likely represented remodeling synapses or dendrites, as previously reported (Bozdagi et al., 2007; Fig. $5 c$, $d$, white arrowheads). Over a period of $60 \mathrm{~min}$ after sham irradiation, we observed a modest but significant increase in FITC-gelatin labeled pericytes (Fig. $5 d, e$, red circle, $g$ ). We further detected an increase in the number of nonpericyte cells in the neuropil, which possessed glial-like morphology (Fig. $5 d, f$, green arrow, $g$ ).

Following the induction of capillary ischemia, we observed a robust increase in FITC-gelatin activation (Fig. 6a). The number of both FITC-gelatin-labeled pericytes and nonpericyte cells was threefold greater than that seen following sham irradiation, over a similar 60 min period of imaging (Fig. 6b). SB-3CT is a potent blocker of both MMP-2 and MMP-9. To better understand the isoform-specific contributions in our model, we examined the effect of an MMP-9-specific inhibitor $\left(\mathrm{C}_{27} \mathrm{H}_{33} \mathrm{~N}_{3} \mathrm{O}_{5} \mathrm{~S}\right)$ or an MMP-2-specific inhibitor (oleoyl-N- hydroxylamide). These inhibitors were coinjected into the brain along with FITC-gelatin since their ability to pass the $\mathrm{BBB}$ was unclear. When the MMP-9 inhibitor was coinjected, the number of labeled pericyte somata was significantly reduced (Fig. 6c). In contrast, coinjection of the MMP-2 inhibitor had no effect on labeled pericyte somata. Nonpericyte cells exhibited the reverse outcome with inhibitors, where the number of labeled cells was reduced with the MMP-2 inhibitor, but not with the MMP-9 inhibitor (Fig. 6d).

\section{Preferential MMP-9 activity and capillary leakage at pericyte somata}

We next examined how these changes in gelatinase activity related to capillary leakage. Capillary flow and leakage in these experiments were observed with an intravenously injected 70 $\mathrm{kDa}$ Texas red-dextran dye, which was imaged concurrent with FITC-gelatin at $800 \mathrm{~nm}$ two-photon excitation using two-channel detection. tdTomato-positive pericytes, which shared an emission spectrum similar to that of Texas reddextran, were distinguished by imaging at a longer twophoton excitation wavelength of $975 \mathrm{~nm}$ at the beginning of each experiment.

Consistent with increased MMP-9 activity causing capillary wall damage, leakage co-occurred with FITC-gelatin activation at pericyte somata (Fig. 7). When multiple pericytes 

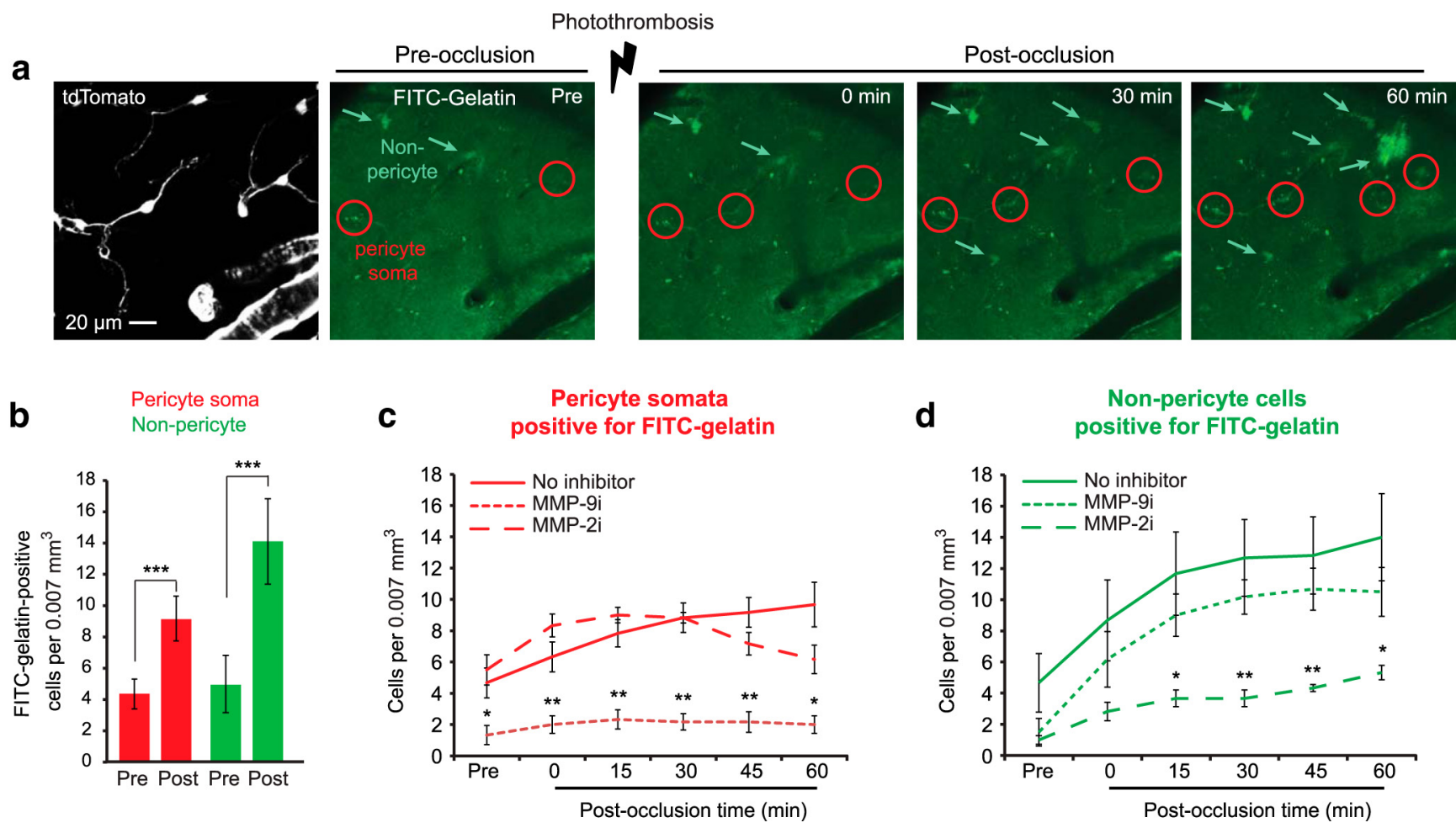

Figure 6. In vivo imaging of FITC-gelatin reveals rapid MMP-9 activation during capillary ischemia. $\boldsymbol{a}$, Location of tdTomato-positive pericytes visualized in a PDGFR $\beta$-tdTomato mouse with representative examples of FITC-gelatin activation at various time points following photothrombotic occlusion of capillaries. Red circles indicate FITC-gelatin-positive pericyte somata, while green arrows indicate the location of FITC-gelatin-positive cells that were not colocalized with tdTomato (nonpericytes). $\boldsymbol{b}$, Mean number of FITC-gelatin-positive pericytes (red) and nonpericyte cells (green) before and $60 \mathrm{~min}$ after photothrombosis. Paired-samples $t$ tests. ${ }^{* * *} p<0.001$ ( $n=9$ occlusion sites over four mice). $\boldsymbol{c}$, Mean number of FITC-gelatin-positive pericyte soma over the experimental time course. $p<0.001$ (main effect). ${ }^{*} p<0.05,{ }^{* *} p<0.01$, compared with the No-Inhibitor group; two-way AN0VA with repeated measures and Greenehouse-Geisser correction. Significance between individual time points was determined by Bonferroni post hoc analysis. MMP-9i, $n=6$ occlusion sites over three mice; MMP-2i, $n=6$ occlusion sites over three mice; Control, $n=9$ occlusion sites over 4 mice. $\boldsymbol{d}$, Mean number of FITC-gelatin-positive nonpericyte cells over the experimental time course. $p<0.001$ (main effect). ${ }^{*} p<0.05,{ }^{* *} p<0.01$, compared with the No Inhibitor group; two-way ANOVA with repeated measures and Greenehouse-Geisser correction. Significance between individual time points was determined by Bonferroni post hoc analysis. Data are shown as the mean \pm SEM.

were visible within a single imaging field, FITC-gelatin activation concentrated around pericyte somata, while intervening regions covered by thin pericyte processes remained comparatively unlabeled (Fig. 7a,b). Upon closer inspection, a clear colocalization could be observed between pericyte somata and FITC-gelatin activation within the first $30 \mathrm{~min}$ of ischemia (Fig. $7 c-e$ ). In some cases, the proximal processes emerging from the pericyte soma were labeled (Fig. 7, white arrowheads: $c, 10 \mathrm{~min}, d, 30 \mathrm{~min})$. In most cases, FITC-gelatin activation at the pericyte soma was followed by extravasation of the intravenous dye (Fig. 7 white arrow: $c, 60 \mathrm{~min}, e, 30 \mathrm{~min}$ ), as was seen in earlier experiments. Within $60 \mathrm{~min}$ postocclusion, gelatinolytic activity would then spread outward from the pericyte soma into the parenchyma or intraluminal space, possibly due to the release of active MMP-9. Consistent with the reduction of FITC-gelatin labeled pericytes (Fig. 6c), coinjection of the MMP-9 inhibitor, but not the MMP-2 inhibitor, significantly reduced the number of leakage sites occurring at pericyte somata (Fig. $7 f$ ). Collectively, these data indicate that pericyte somata are a locus of rapid, MMP-9-dependent capillary wall damage during ischemia.

FITC-gelatin activation was observed at all leakage sites examined, regardless of the presence of a pericyte soma (100\% of 61 leakage sites over five mice). FITC-gelatin activation at sites without a pericyte soma involved either capillary contact by the processes of a FITC-gelatin-labeled glial-like cell (Fig. 8a, white arrowhead), or localized perivascular FITC-gelatin activation
(Fig. 8b). However, the number of nonpericyte leakage sites was not reduced by MMP-9 or MMP-2 inhibitors (Fig. 8c). This finding indicates that there are multiple cellular sources of gelatinase activity induced during capillary ischemia, and that these varied sources may respond to different inhibitor concentrations than that effective for mitigating pericyte-specific MMP-9 activity and leakage.

\section{Discussion}

A major goal in stroke research is to understand and control processes that lead to BBB disruption (Sandoval and Witt, 2008). In this study, we have used an in vivo two-photon imaging approach with a novel capillary ischemia model to demonstrate that pericyte somata are a previously undefined locus of heightened BBB disruption. We find that FITC-gelatin activation precedes leakage at pericyte somata and can be blocked by MMP-9 inhibition, but not MMP-2 inhibition (Fig. $9 a-c$ ). Further, leakage occurs only after the complete cessation of flow in the adjoining capillary (Fig. 9d). Our results indicate that pericyte somata are found along only $7 \%$ of the cortical capillary network, yet account for $\sim 80 \%$ of the sites for localized plasma leakage. Although pericyte-specific leakage occurs within a small fraction of the total capillary network, blood-borne molecules that enter the brain through this route may diffuse and affect brain function distant to the site of leakage. Developing strategies to reduce capillary leakage at pericyte somata may help to protect the brain during stroke, and possibly other neurological diseases involving 
a

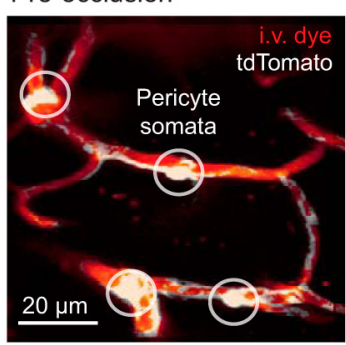

b

Post-occlusion (30 min)

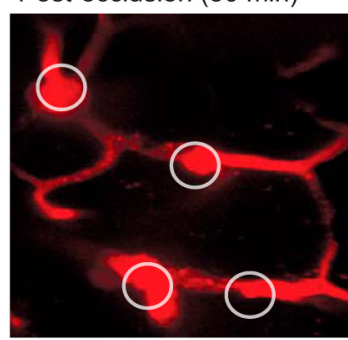

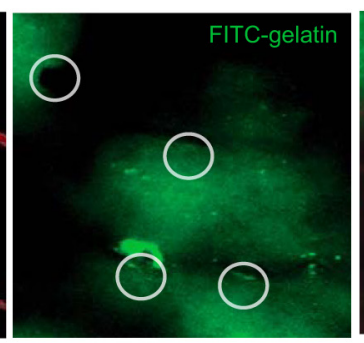
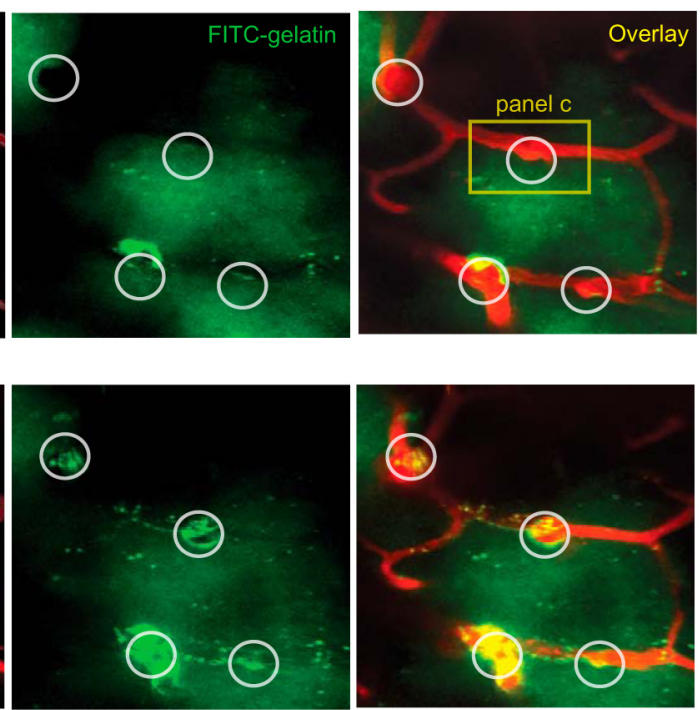

C
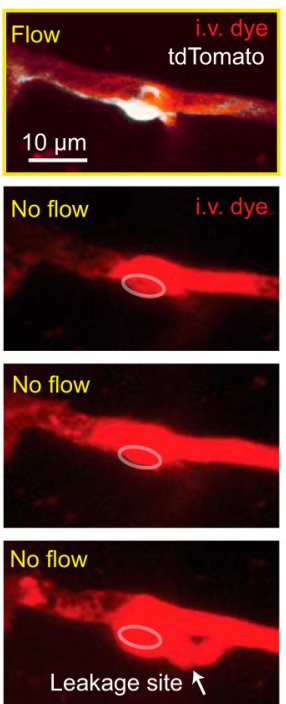
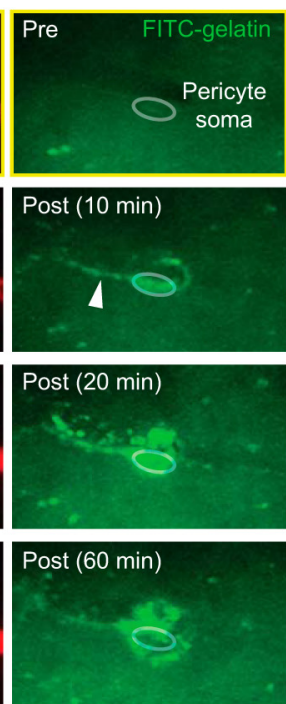

d
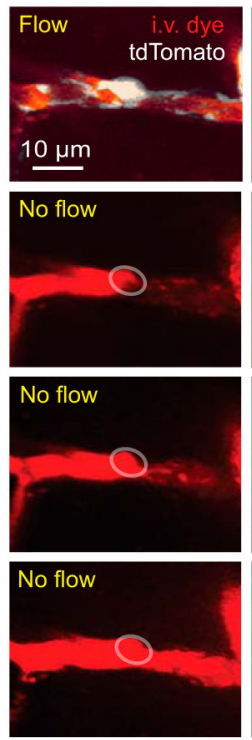
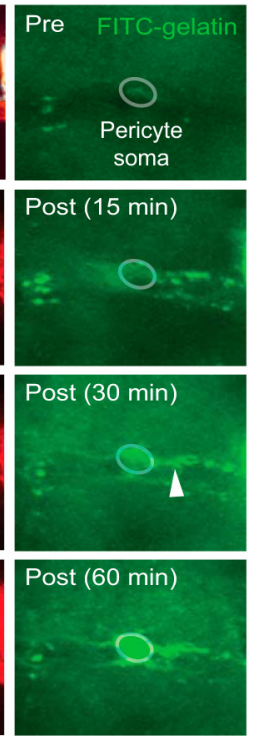
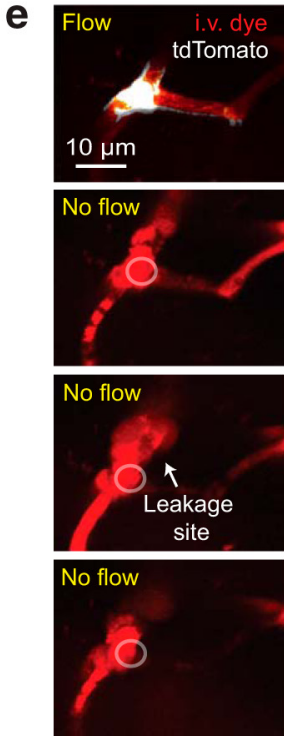
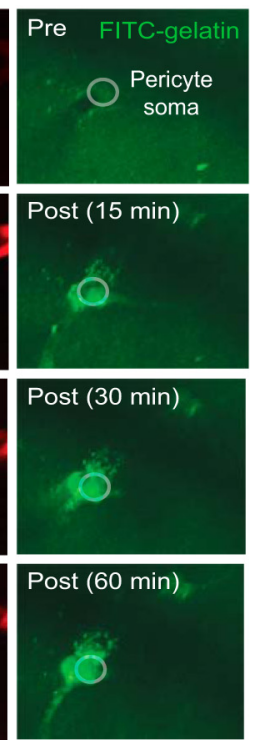

f

Leakage sites occurring at pericyte somata

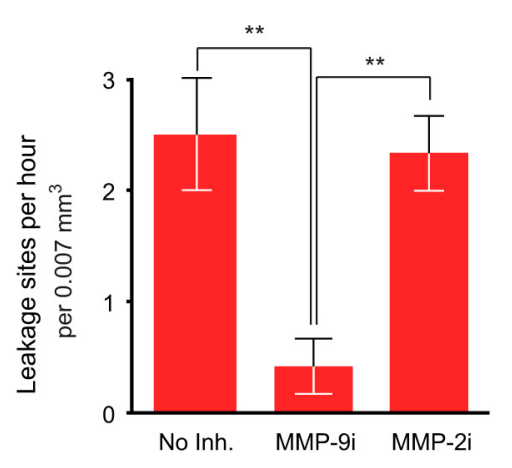

Figure 7. In vivo imaging of FITC-gelatin reveals rapid MMP-9 activation at pericyte somata before capillary leakage. $\boldsymbol{a}, \boldsymbol{b}$, Representative wide-field images showing the location of pericyte somata (white circles, tdTomato), capillaries (intravenous dye) and FITC-gelatin activation before $(\boldsymbol{a})$ and 30 min following (b) photothrombosis. $\boldsymbol{c}-\boldsymbol{e}$, Representative high-magnification images showing the precise location of pericyte soma (white, circles) on capillaries (red) and FITC-gelatin activation (green) over the experimental time course. White arrowheads refer to FITC-gelatin activation on proximal processes of pericytes. White arrows indicate the first observation of capillary leakage. The example in $\boldsymbol{d}$ shows FITC-gelatin activation at the pericyte soma, but no obvious leakage over the imaging time course. $f$, Mean number of leakage sites occurring at pericyte somata with and without coinjection of isoform-specific inhibitors of MMP-9 (MMP-9i) and MMP-2 (MMP-2i). ${ }^{* *} p<0.01$; one-way ANOVA. MMP-9i, $n=6$ occlusion sites over four mice; MMP-2i, $n=6$ occlusion sites over three mice; Control, $n=9$ occlusion sites over four mice. Data are shown as the mean \pm SEM.

capillary flow impairment such as traumatic brain injury (Sword et al., 2013; Østergaard et al., 2014) and dementia (Farkas and Luiten, 2001; Østergaard et al., 2016).

These findings support and build on our current understanding of the acute pericyte response to ischemia/injury. Recent studies by Hall et al. (2014) revealed a specific vulnerability of pericytes during simulated ischemia in brain slices and in vivo following middle cerebral artery occlusion. While the loss of pericyte viability was suspected to cause BBB leakage, the underlying mechanism of vascular damage, the timing of injury processes, and the relation to capillary flow remained unclear. We show that one mechanism is the rapid mobilization of MMP-9 from pericyte somata (within tens of minutes) during capillary ischemia. We suggest that pericytes themselves are the source of MMP-9, based on the marked colocalization between FITC-gelatin and tdTomato-positive pericytes during early stages of MMP-9 activation (Fig. 7). Since the soma is the largest subcellular compartment of the pericyte, and likely harbors the most MMP-9 protein, it is reasonable to expect the most potent FITC-gelatin activation and leakage at the soma. Other studies also support the idea that pericytes are sources of MMP-9. In culture, human pericytes induce MMP-9 activity, but not MMP-2 (Takahashi et al., 2014). Cultured rat pericytes release more MMP-9 than either endothelial cells or astrocytes following thrombin treatment (Machida et al., 2015). Further, cerebral pericytes in Apoe-deficient and APOE4 transgenic mice express higher MMP-9 levels through a cyclophilin-nuclear factor- $\kappa$ B pathway (Bell et al., 2012). Given the rapid nature of FITC-gelatin unquenching in the current in 
a
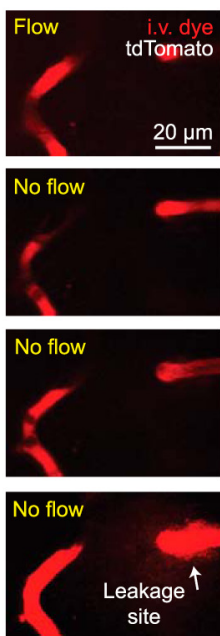

b
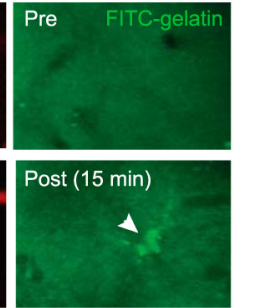

Post (30 min)
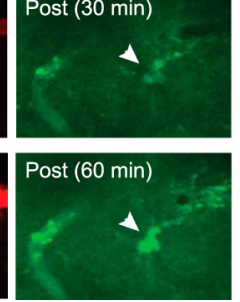
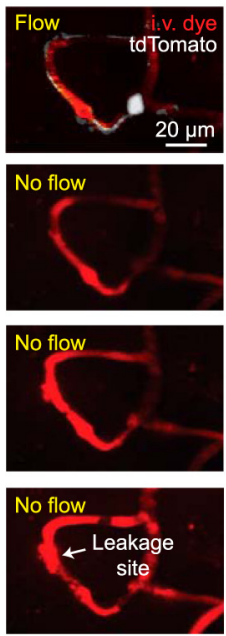

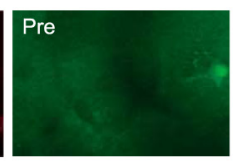

Post (15 min)

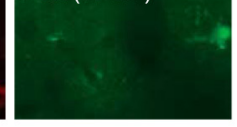

Post (30 min)
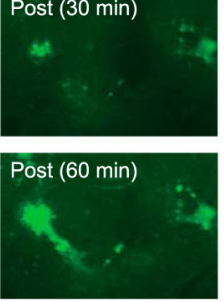

C

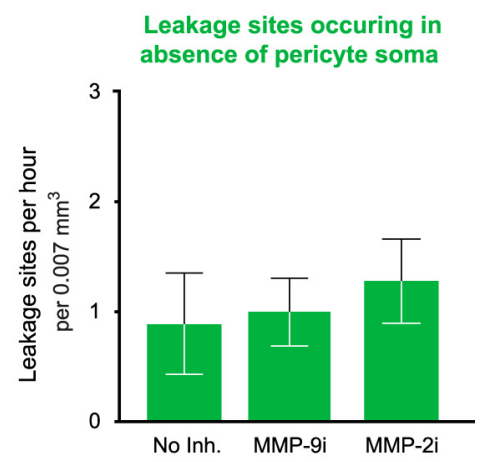

Figure 8. Ischemia-induced FITC-gelatin activation and capillary leakage occurring in regions without a pericyte soma. $\boldsymbol{a}, \boldsymbol{b}$, Representative high-magnification images showing the location of FITC-gelatin activation over the experimental time course. Pericytes, where present within the image field, are indicated by tdTomato labeling (white). $\boldsymbol{a}$, A parenchymal cell with glial morphology contacting the leaking capillary (white arrowhead). $\boldsymbol{b}$, A perivascular region of FITC-gelatin activation distant from the pericyte soma. $\boldsymbol{c}$, Mean number of leakage sites occurring in the absence of pericyte somata with and without coinjection of isoform-specific inhibitors of MMP- 9 and MMP-2. No significance was found with one-way ANOVA. MMP-9i, $n=6$ occlusion sites over three mice; MMP-2i, $n=6$ occlusion sites over three mice; Control, $n=9$ occlusion sites over four mice. Data are shown as the mean \pm SEM.

vivo study, it is conceivable that pericytes activate a pool of pro-MMP-9 zymogens through a nontranscriptional route, such as $S$-nitrosylation (Gu et al., 2005). If so, pre-existing comorbidities that promote MMP-9 expression in pericytes could lead to more severe responses during ischemic injury.

Recent studies have proposed a stepwise process for $\mathrm{BBB}$ disruption during ischemia, where leakage by endothelial transcytosis (transcellular leakage) precedes the degradation of the tight junctions (paracellular leakage) (Knowland et al., 2014). We postulate that leakage at pericyte somata is an intermediate step between these classic forms of BBB disruption. The concentrated activation of MMP-9 at the pericyte somata likely leads to degradation of the underlying tight junction complexes (Yang et al., 2007), while the intervening regions of the capillary bed maintain tight junction integrity but exhibit increased endothelial caveolae (Krueger et al., 2013; Nahirney et al., 2016). If so, there may be conditions under which both transcellular and paracellular leakage routes coexist along the same capillary segments. In a typical middle cerebral artery stroke, leakage at pericyte somata might occur within, and just beyond, the ischemic core, where some capillaries are expected to be completely blocked (Srinivasan et al., 2013). Indeed, similar plumes of leakage have been observed with electron microscopy during middle cerebral artery stroke (Ohtake et al., 2004). Unexpectedly, past imaging studies have shown that leaked blood components do not significantly affect neuron structure or function in the acute time frame of hours (Zhang and Murphy, 2007; Cianchetti et al., 2013).

d

\section{Pericyte soma-specific events}
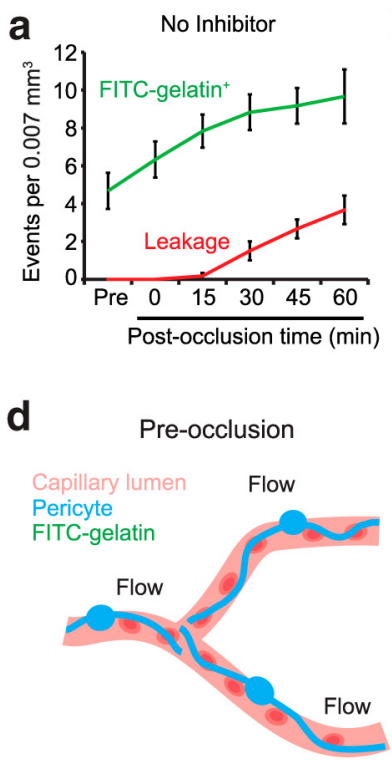

Figure 9. Summary diagram of BBB disruption at pericyte somata. $\boldsymbol{a}-\boldsymbol{c}$, Summary data showing the mean number of leakage sites occurring at pericyte somata (red line) and the number of FITC-gelatin-positive pericyte somata over $1 \mathrm{~h}$ of imaging. Coinjection of an MMP-9 inhibitor reduces both FITC-gelatin activation and capillary leakage at pericyte somata, while an MMP- 2 inhibitor has comparatively no effect. Data are shown as the mean \pm SEM. $\boldsymbol{d}$, Nonflowing capillaries (no red blood cells) in the imaged region will experience $B B B$ disruption at pericyte somata, while closely neighboring capillaries with flow remain intact. Rapid activation and release of MMP-9 at the pericyte soma damages the capillary wall in a focal manner.
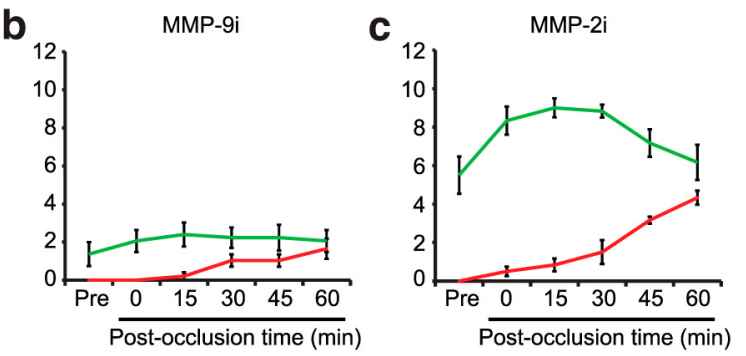

Post-occlusion (15 minutes)
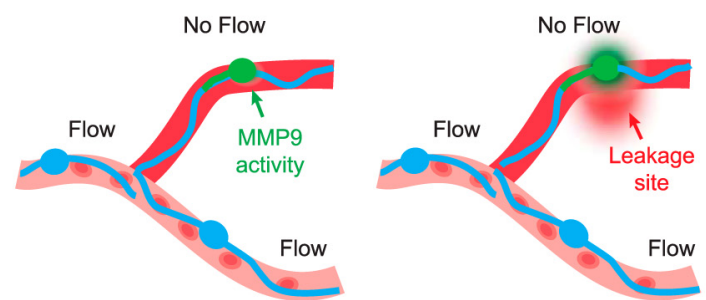

However, the impact of the delayed inflammatory responses to capillary leakage, which occur over days to weeks following injury, remains to be examined.

We showed overlap between FITC-gelatin probe activation and pericyte somata, providing evidence that pericytes may be a source of MMP-9 in vivo (Fig. 7). However, we have not modulated pericytes in a cell-specific manner to confirm this idea. The barrier to such an experiment is that the manipulation of pericyte signaling or migration would itself compromise the BBB (Armulik et al., 2010; Bell et al., 2010; Daneman et al., 2010), altering 
basal MMP-9 expression/activity profiles in pericytes and other cell types. Thus, it remains possible that pericytes interact closely with neighboring endothelial cells (Zozulya et al., 2008) or leukocytes (Stark et al., 2013) to activate MMP-9 during ischemia. While numerous cellular sources of MMP-9 have been demonstrated in stroke models, including neutrophils, microglia, astrocytes, or endothelial cells (Justicia et al., 2003; Gidday et al., 2005; Rosell et al., 2006; Zhao et al., 2006; del Zoppo et al., 2012), the key finding of the current study is the striking enrichment of MMP-9 activity at pericyte somata and the speed of its activation, warranting further investigation of this phenomenon in other models of stroke and cerebrovascular disease. Future studies are needed to better understand the mechanisms that control rapid MMP-9 activation at pericyte somata, and how pericytes contribute to overall BBB disruption in different disease states. Further, it will also be important to determine whether pericytes die (Hall et al., 2014) or use MMP-9 to actively migrate from the endothelium (Dore-Duffy et al., 2000), as their long-term fate may also be important for tissue revascularization and recovery.

\section{References}

Armulik A, Abramsson A, Betsholtz C (2005) Endothelial/pericyte interactions. Circ Res 97:512-523. CrossRef Medline

Armulik A, Genové G, Mäe M, Nisancioglu MH, Wallgard E, Niaudet C, $\mathrm{He}$ L, Norlin J, Lindblom P, Strittmatter K, Johansson BR, Betsholtz C (2010) Pericytes regulate the blood-brain barrier. Nature 468:557-561. CrossRef Medline

Attwell D, Mishra A, Hall CN, O'Farrell FM, Dalkara T (2016) What is a pericyte? J Cereb Blood Flow Metab 36:451-455. CrossRef Medline

Barr TL, Latour LL, Lee KY, Schaewe TJ, Luby M, Chang GS, El-Zammar Z, Alam S, Hallenbeck JM, Kidwell CS, Warach S (2010) Blood-brain barrier disruption in humans is independently associated with increased matrix metalloproteinase-9. Stroke 41:e123-e128. CrossRef Medline

Bell RD, Winkler EA, Sagare AP, Singh I, LaRue B, Deane R, Zlokovic BV (2010) Pericytes control key neurovascular functions and neuronal phenotype in the adult brain and during brain aging. Neuron 68:409-427. CrossRef Medline

Bell RD, Winkler EA, Singh I, Sagare AP, Deane R, Wu Z, Holtzman DM, Betsholtz C, Armulik A, Sallstrom J, Berk BC, Zlokovic BV (2012) Apolipoprotein E controls cerebrovascular integrity via cyclophilin A. Nature 485:512-516. CrossRef Medline

Ben-Zvi A, Lacoste B, Kur E, Andreone BJ, Mayshar Y, Yan H, Gu C (2014) Mfsd2a is critical for the formation and function of the blood-brain barrier. Nature 509:507-511. CrossRef Medline

Blinder P, Tsai PS, Kaufhold JP, Knutsen PM, Suhl H, Kleinfeld D (2013) The murine cortical angiome: an interconnected vascular network with noncolumnar patterns of blood flow. Nat Neurosci 16:889-897. CrossRef Medline

Bozdagi O, Nagy V, Kwei KT, Huntley GW (2007) In vivo roles for matrix metalloproteinase-9 in mature hippocampal synaptic physiology and plasticity. J Neurophysiol 98:334-344. CrossRef Medline

Broadwell RD, Salcman M, Kaplan RS (1982) Morphologic effect of dimethyl sulfoxide on the blood-brain barrier. Science 217:164-166. CrossRef Medline

Chen B, Friedman B, Cheng Q, Tsai P, Schim E, Kleinfeld D, Lyden PD (2009) Severe blood brain barrier disruption and surrounding tissue injury. Stroke 40:e666-e674. CrossRef Medline

Cianchetti FA, Kim DH, Dimiduk S, Nishimura N, Schaffer CB (2013) Stimulus-evoked calcium transients in somatosensory cortex are temporarily inhibited by a nearby microhemorrhage. PLoS One 8:e65663. CrossRef Medline

Cuttler AS, LeClair RJ, Stohn JP, Wang Q, Sorenson CM, Liaw L, Lindner V (2011) Characterization of Pdgfrb-Cre transgenic mice reveals reduction of ROSA26 reporter activity in remodeling arteries. Genesis 49:673-680. CrossRef Medline

Daneman R, Zhou L, Kebede AA, Barres BA (2010) Pericytes are required for blood-brain barrier integrity during embryogenesis. Nature 468:562_566. CrossRef Medline

del Zoppo GJ, Frankowski H, Gu YH, Osada T, Kanazawa M, Milner R, Wang
X, Hosomi N, Mabuchi T, Koziol JA (2012) Microglial cell activation is a source of metalloproteinase generation during hemorrhagic transformation. J Cereb Blood Flow Metab 32:919-932. CrossRef Medline

Desilles JP, Rouchaud A, Labreuche J, Meseguer E, Laissy JP, Serfaty JM, Lapergue B, Klein IF, Guidoux C, Cabrejo L, Sirimarco G, Lavallée PC, Schouman-Claeys E, Amarenco P, Mazighi M (2013) Blood-brain barrier disruption is associated with increased mortality after endovascular therapy. Neurology 80:844-851. CrossRef Medline

Dore-Duffy P, Owen C, Balabanov R, Murphy S, Beaumont T, Rafols JA (2000) Pericyte migration from the vascular wall in response to traumatic brain injury. Microvasc Res 60:55-69. CrossRef Medline

Duz B, Oztas E, Erginay T, Erdogan E, Gonul E (2007) The effect of moderate hypothermia in acute ischemic stroke on pericyte migration: an ultrastructural study. Cryobiology 55:279-284. CrossRef Medline

Farkas E, Luiten PG (2001) Cerebral microvascular pathology in aging and Alzheimer's disease. Prog Neurobiol 64:575-611. CrossRef Medline

Fernández-Klett F, Offenhauser N, Dirnagl U, Priller J, Lindauer U (2010) Pericytes in capillaries are contractile in vivo, but arterioles mediate functional hyperemia in the mouse brain. Proc Natl Acad Sci U S A 107: 22290-22295. CrossRef Medline

Garcia-Alloza M, Prada C, Lattarulo C, Fine S, Borrelli LA, Betensky R, Greenberg SM, Frosch MP, Bacskai BJ (2009) Matrix metalloproteinase inhibition reduces oxidative stress associated with cerebral amyloid angiopathy in vivo in transgenic mice. J Neurochem 109:1636-1647. CrossRef Medline

Gidday JM, Gasche YG, Copin JC, Shah AR, Perez RS, Shapiro SD, Chan PH, Park TS (2005) Leukocyte-derived matrix metalloproteinase-9 mediates blood-brain barrier breakdown and is proinflammatory after transient focal cerebral ischemia. Am J Physiol Heart Circ Physiol 289: H558-H568. CrossRef Medline

Gu Z, Cui J, Brown S, Fridman R, Mobashery S, Strongin AY, Lipton SA (2005) A highly specific inhibitor of matrix metalloproteinase-9 rescues laminin from proteolysis and neurons from apoptosis in transient focal cerebral ischemia. J Neurosci 25:6401-6408. CrossRef Medline

Gurney KJ, Estrada EY, Rosenberg GA (2006) Blood-brain barrier disruption by stromelysin-1 facilitates neutrophil infiltration in neuroinflammation. Neurobiol Dis 23:87-96. CrossRef Medline

Hall CN, Reynell C, Gesslein B, Hamilton NB, Mishra A, Sutherland BA, O'Farrell FM, Buchan AM, Lauritzen M, Attwell D (2014) Capillary pericytes regulate cerebral blood flow in health and disease. Nature 508 : 55-60. CrossRef Medline

Hartmann DA, Underly RG, Grant RI, Watson AN, Lindner V, Shih AY (2015) Pericyte structure and distribution in the cerebral cortex revealed by high-resolution imaging of transgenic mice. Neurophotonics 2:041402. CrossRef Medline

Hawkins BT, Davis TP (2005) The blood-brain barrier/neurovascular unit in health and disease. Pharmcol Rev 57:173-185. CrossRef Medline

Hellström M, Kalén M, Lindahl P, Abramsson A, Betsholtz C (1999) Role of PDGF-B and PDGFR-beta in recruitment of vascular smooth muscle cells and pericytes during embryonic blood vessel formation in the mouse. Development 126:3047-3055. Medline

Hill RA, Tong L, Yuan P, Murikinati S, Gupta S, Grutzendler J (2015) Regional blood flow in the normal and ischemic brain is controlled by arteriolar smooth muscle cell contractility and not by capillary pericytes. Neuron 87:95-110. CrossRef Medline

Justicia C, Panés J, Solé S, Cervera A, Deulofeu R, Chamorro A, Planas AM (2003) Neutrophil infiltration increases matrix metalloproteinase-9 in the ischemic brain after occlusion/reperfusion of the middle cerebral artery in rats. J Cereb Blood Flow Metab 23:1430-1440. Medline

Knowland D, Arac A, Sekiguchi KJ, Hsu M, Lutz SE, Perrino J, Steinberg GK, Barres BA, Nimmerjahn A, Agalliu D (2014) Stepwise recruitment of transcellular and paracellular pathways underlies blood-brain barrier breakdown in stroke. Neuron 82:603-617. CrossRef Medline

Krueger M, Härtig W, Reichenbach A, Bechmann I, Michalski D (2013) Blood-brain barrier breakdown after embolic stroke in rats occurs without ultrastructural evidence for disrupting tight junctions. PLoS One 8:e56419. CrossRef Medline

Larrue V, von Kummer R, del Zoppo G, Bluhmki E (1997) Hemorrhagic transformation in acute ischemic stroke: potential contributing factors in the European Cooperative Acute Stroke study. Stroke 28:957-960. CrossRef Medline

Lee SR, Kim HY, Rogowska J, Zhao BQ, Bhide P, Parent JM, Lo EH (2006) 
Involvement of matrix metalloproteinase in neuroblast cell migration from the subventricular zone after stroke. J Neurosci 26:3491-3495. CrossRef Medline

Lindahl P, Johansson BR, Levéen P, Betsholtz C (1997) Pericyte loss and microaneurysm formation in PDGF-B-deficient mice. Science 277:242245. CrossRef Medline

Liu S, Agalliu D, Yu C, Fisher M (2012) The role of pericytes in blood-brain barrier function and stroke. Curr Pharm Des 18:3653-3662. CrossRef Medline

Machida T, Takata F, Matsumoto J, Takenoshita H, Kimura I, Yamauchi A, Dohgu S, Kataoka Y (2015) Brain pericytes are the most thrombin-sensitive matrix metalloproteinase-9-releasing cell type constituting the blood-brain barrier in vitro. Neurosci Lett 599:109114. CrossRef Medline

Madisen L, Zwingman TA, Sunkin SM, Oh SW, Zariwala HA, Gu H, Ng LL, Palmiter RD, Hawrylycz MJ, Jones AR, Lein ES, Zeng H (2010) A robust and high-throughput Cre reporting and characterization system for the whole mouse brain. Nat Neurosci 13:133-140. CrossRef Medline

Mostany R, Portera-Cailliau C (2008) A method for 2-photon imaging of blood flow in the neocortex through a cranial window. J Vis Exp 12:678. CrossRef Medline

Nahirney PC, Reeson P, Brown CE (2016) Ultrastructural analysis of bloodbrain barrier breakdown in the peri-infarct zone in young and aged mice. J Cereb Blood Flow Metab 36:413-425. CrossRef Medline

Neurology Working Group of the Cohorts for Heart and Aging Research in Genomic Epidemiology (CHARGE) Consortium, Stroke Genetics Network (SiGN), International Stroke Genetics Consortium (ISGC) (2016) Identification of additional risk loci for stroke and small vessel disease: a meta-analysis of genome-wide association studies. Lancet Neurol 15:695707. CrossRef Medline

Ohtake M, Morino S, Kaidoh T, Inoué T (2004) Three-dimensional structural changes in cerebral microvessels after transient focal cerebral ischemia in rats: scanning electron microscopic study of corrosion casts. Neuropathology 24:219-227. CrossRef Medline

Østergaard L, Engedal TS, Aamand R, Mikkelsen R, Iversen NK, Anzabi M, Næss-Schmidt ET, Drasbek KR, Bay V, Blicher JU, Tietze A, Mikkelsen IK, Hansen B, Jespersen SN, Juul N, Sørensen JC, Rasmussen M (2014) Capillary transit time heterogeneity and flow-metabolism coupling after traumatic brain injury. J Cereb Blood Flow Metab 34: 1585-1598. CrossRef Medline

Østergaard L, Engedal TS, Moreton F, Hansen MB, Wardlaw JM, Dalkara T, Markus HS, Muir KW (2016) Cerebral small vessel disease: capillary pathways to stroke and cognitive decline. J Cereb Blood Flow Metab 36:302-325. CrossRef Medline

Peppiatt CM, Howarth C, Mobbs P, Attwell D (2006) Bidirectional control of CNS capillary diameter by pericytes. Nature 443:700-704. CrossRef Medline

Reyahi A, Nik AM, Ghiami M, Gritli-Linde A, Pontén F, Johansson BR, Carlsson P (2015) Foxf2 is required for brain pericyte differentiation and development and maintenance of the blood-brain barrier. Dev Cell 34:19-32. CrossRef Medline

Rosell A, Ortega-Aznar A, Alvarez-Sabín J, Fernández-Cadenas I, Ribó M, Molina CA, Lo EH, Montaner J (2006) Increased brain expression of matrix metalloproteinase- 9 after ischemic and hemorrhagic human stroke. Stroke 37:1399-1406. CrossRef Medline

Sandoval KE, Witt KA (2008) Blood-brain barrier tight junction permeability and ischemic stroke. Neurobiol Dis 32:200-219. CrossRef Medline

Shih AY, Driscoll JD, Drew PJ, Nishimura N, Schaffer CB, Kleinfeld D (2012) Two-photon microscopy as a tool to study blood flow and neurovascular coupling in the rodent brain. J Cereb Blood Flow Metab 32:1277-1309. CrossRef Medline

Shih AY, Blinder P, Tsai PS, Friedman B, Stanley G, Lyden PD, Kleinfeld D (2013) The smallest stroke: occlusion of one penetrating vessel leads to infarction and a cognitive deficit. Nat Neurosci 16:55-63. CrossRef Medline

Smith AC, Kupchik YM, Scofield MD, Gipson CD, Wiggins A, Thomas CA,
Kalivas PW (2014) Synaptic plasticity mediating cocaine relapse requires matrix metalloproteinases. Nat Neurosci 17:1655-1657. CrossRef Medline

Srinivasan VJ, Mandeville ET, Can A, Blasi F, Climov M, Daneshmand A, Lee JH, Yu E, Radhakrishnan H, Lo EH, Sakadžić S, Eikermann-Haerter K, Ayata C (2013) Multiparametric, longitudinal optical coherence tomography reveals acute injury and chronic recovery in experimental ischemic stroke. PLoS One 8:e71478. CrossRef Medline

Stark K, Eckart A, Haidari S, Tirniceriu A, Lorenz M, von Brühl ML, Gärtner F, Khandoga AG, Legate KR, Pless R, Hepper I, Lauber K, Walzog B, Massberg S (2013) Capillary and arteriolar pericytes attract innate leukocytes exiting through venules and "instruct" them with patternrecognition and motility programs. Nat Immunol 14:41-51. CrossRef Medline

Sword J, Masuda T, Croom D, Kirov SA (2013) Evolution of neuronal and astroglial disruption in the peri-contusional cortex of mice revealed by in vivo two-photon imaging. Brain 136:1446-1461. CrossRef Medline

Takahashi A, Park HK, Melgar MA, Alcocer L, Pinto J, Lenzi T, Diaz FG, Rafols JA (1997) Cerebral cortex blood flow and vascular smooth muscle contractility in a rat model of ischemia: a correlative laser Doppler flowmetric and scanning electron microscopic study. Acta Neuropathol 93:354-368. CrossRef Medline

Takahashi Y, Maki T, Liang AC, Itoh K, Lok J, Osumi N, Arai K (2014) p38 MAP kinase mediates transforming-growth factor- $\beta 1$-induced upregulation of matrix metalloproteinase- 9 but not -2 in human brain pericytes. Brain Res 1593:1-8. CrossRef Medline

Takata F, Dohgu S, Matsumoto J, Takahashi H, Machida T, Wakigawa T, Harada E, Miyaji H, Koga M, Nishioku T, Yamauchi A, Kataoka Y (2011) Brain pericytes among cells constituting the blood-brain barrier are highly sensitive to tumor necrosis factor- $\alpha$, releasing matrix metalloproteinase-9 and migrating in vitro. J Neuroinflammation 8:106. CrossRef Medline

Taylor ZJ, Hui ES, Watson AN, Nie X, Deardorff RL, Jensen JH, Helpern JA, Shih AY (2016) Microvascular basis for growth of small infarcts following occlusion of single penetrating arterioles in mouse cortex. J Cereb Blood Flow Metab 36:1357-1373. CrossRef Medline

Thanabalasundaram G, Schneidewind J, Pieper C, Galla HJ (2011) The impact of pericytes on the blood-brain barrier integrity depends critically on the pericyte differentiation stage. Int J Biochem Cell Biol 43:1284-1293.

Weekman EM, Wilcock DM (2015) Matrix metalloproteinase in bloodbrain barrier breakdown in dementia. J Alzheimers Dis 49:893-903. CrossRef Medline

Winkler EA, Bell RD, Zlokovic BV (2011) Central nervous system pericytes in health and disease. Nat Neurosci 14:1398-1405. CrossRef Medline

Yang Y, Estrada EY, Thompson JF, Liu W, Rosenberg GA (2007) Matrix metalloproteinase-mediated disruption of tight junction proteins in cerebral vessels is reversed by synthetic matrix metalloproteinase inhibitor in focal ischemia in rat. J Cereb Blood Flow Metab 27:697-709. CrossRef Medline

Yemisci M, Gursoy-Ozdemir Y, Vural A, Can A, Topalkara K, Dalkara T (2009) Pericyte contraction induced by oxidative-nitrative stress impairs capillary reflow despite successful opening of an occluded cerebral artery. Nat Med 15:1031-1037. CrossRef Medline

Zhang S, Murphy TH (2007) Imaging the impact of cortical microcirculation on synaptic structure and sensory-evoked hemodynamic responses in vivo. PLoS Biol 5:e119. CrossRef Medline

Zhao BQ, Wang S, Kim HY, Storrie H, Rosen BR, Mooney DJ, Wang X, Lo EH (2006) Role of matrix metalloproteinases in delayed cortical responses after stroke. Nat Med 12:441-445. CrossRef Medline

Zhu X, Hill RA, Dietrich D, Komitova M, Suzuki R, Nishiyama A (2011) Age-dependent fate and lineage restriction of single NG2 cells. Development 138:745-753. CrossRef Medline

Zozulya A, Weidenfeller C, Galla HJ (2008) Pericyte-endothelial cell interaction increases MMP-9 secretion at the blood-brain barrier in vitro. Brain Res 1189:1-11. CrossRef Medline 